Tinbergen Institute Discussion Paper

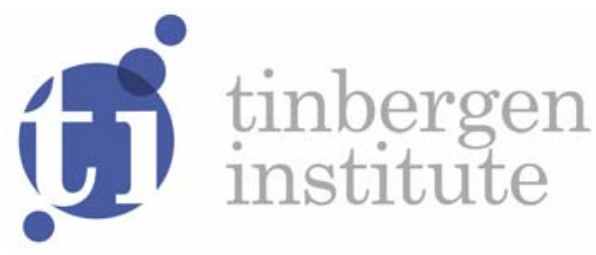

\title{
Language Proficiency of Migrants: \\ The Relation with Job Satisfaction and Skill Matching
}

Hans G. Bloemen 
Tinbergen Institute is the graduate school and research institute in economics of Erasmus University Rotterdam, the University of Amsterdam and VU University Amsterdam.

More TI discussion papers can be downloaded at http://www.tinbergen.nl

Tinbergen Institute has two locations:

Tinbergen Institute Amsterdam

Gustav Mahlerplein 117

1082 MS Amsterdam

The Netherlands

Tel.: +31(0)205251600

Tinbergen Institute Rotterdam

Burg. Oudlaan 50

3062 PA Rotterdam

The Netherlands

Tel.: +31(0)10 4088900

Fax: $+31(0) 104089031$

Duisenberg school of finance is a collaboration of the Dutch financial sector and universities, with the ambition to support innovative research and offer top quality academic education in core areas of finance.

DSF research papers can be downloaded at: http://www.dsf.nl/

Duisenberg school of finance

Gustav Mahlerplein 117

1082 MS Amsterdam

The Netherlands

Tel.: +31(0)20 5258579 


\title{
Language proficiency of migrants: the relation with job satisfaction and skill matching
}

by

\author{
Hans G. Bloemen \\ Tinbergen Institute, Amsterdam, \\ IZA, Bonn, \\ Netspar, and Department of Economics \\ VU University Amsterdam \\ De Boelelaan 1105 \\ 1081 HV Amsterdam \\ The Netherlands
}

This version November 2014

\begin{abstract}
We empirically analyze the language proficiency of migrants in the Netherlands. Traditionally, the emphasis in studying language proficiency and economic outcomes has been on the relation between earnings and indicators for language proficiency, motivated by the human capital theory. Here we analyze whether there is a relation between proficiency of the destination language and job level. A lack of language skills may induce the migrant to work in jobs of a lower level leading to lower job satisfaction. We use subjective survey information about job satisfaction and the fit between the migrant's education and skill level and the job. We also use objective information on professional level. Our estimation strategy allows for unobservable correlations between language proficiency and labour market outcomes by employing a simultaneous two equations framework which also exploits the panel nature of our data, by allowing for time persistent random effects. We use a variety of different instrumental variables, some of which are related to linguistic distance, to shed light on the robustness of the results. For men, we find evidence for a positive relationship between indicators for language proficiency and satisfaction with work type and professional level. For women, no impact of language proficiency on the level of the job can be found. Rather, women with lower proficiency levels are not selected into employment in the first place.

Email: h.g.bloemen@vu.nl, phone: +31 20 5986037, fax: +31 205989870.

This paper draws on data of the LISS panel of CentERdata. This paper benefited from comments by Federica Teppa, and (seminar and conference) participants at UAB Barcelona, the MESS Workshop, ESEM, Université Paris I, Oded Galor and other participants at the IZA Migration Meeting, University of Basque Country in Bilbao, Alexander Humboldt Seminar Mannheim.
\end{abstract}




\section{Introduction}

Are migrants selected into lower level and less satisfactory jobs due to a lack of proficiency in the destination country's language? The aim of this study is to analyze this question using data from the Longitudinal Internet Studies for the Social Sciences (LISS) for the Netherlands as a destination country. The literature, of which Chiswick (2007) provides an overview, shows that the language proficiency of migrants has a potential impact on labour market outcomes. Most often analyzed is the relation between language proficiency and earnings, recognizing that language skills are part of the individual's human capital.

By our analysis we aim to provide more insight in the channel by which destination language skills affect labour market outcomes. If there were only a pure human capital impact of destination language proficiency on earnings, we would still have the migrant with the appropriate skills in the right job, albeit with a lower wage. The acquisition of additional destination language skills, possibly supported by the employer, then could help the migrant to grow in his or her current job. We have an inherently different labour market situation if a migrant with a given set of skills ends up in a lower level job, at the wrong place and maybe with the wrong employer. Although such a situation may provide the migrant with an additional stimulus to acquire destination country language skills (if he or she is aware of the mechanism), a lack of attractive job offers and the existence of labour market frictions can also be discouraging. Moreover, in this situation we cannot expect much of a current employer in playing a role in supporting a migrant in acquiring destination language skills. Instead, government policy may be required to obtain a more efficient skill matching of migrants in the labour market.

The literature addresses the determinants of the migrant's language proficiency. There are studies for different destination countries, with different destination languages. Chiswick and Miller $(1994,2001)$ provide evidence for Canada, with English as the main language of destination, while Chiswick (1998) studies the case of Israel, and Dustmann (1994) and Dustmann and Van Soest (2001) analyze Germany. Dustmann and Fabbri (2003) not only

analyze earnings as an outcome variable but also employment. Gonzalez (2010) does an analysis for Spain and finds effects of host language skills on employment but not on earnings. 
The destination language of our analysis is Dutch. As pointed out by Chiswick (2007) it is interesting to analyze destination languages that are less common than the English language. Moreover, the Netherlands has a rich variation in the migrant population. ${ }^{1}$ To address the question whether migrants with lower proficiency levels are selected into lower level jobs, we use both subjective and objective outcome measures. The LISS survey contains a direct question to respondents to indicate whether education or skills suit the work that they perform. We analyze whether the response to that question is influenced by language proficiency. In addition, we analyze whether satisfaction with various aspects of the job depends on proficiency. Job satisfaction is also considered as an outcome variable in the education mismatch literature, albeit in different ways. Chevalier (2003) uses information about job satisfaction, together with other job features, to construct a measure of mismatch. Mavromaras et al. (2010) use job satisfaction directly as an outcome variable, like we do in our analysis. Their motivation for using job satisfaction an an outcome is that it not only provides information about restrictions faced by the worker, but it also incorporates the worker's preferences: a low job level relative to the education level may have been the result of choice, rather than restriction. ${ }^{2}$ Applying it to the context of migration, a relatively low job level need not lead to dissatisfaction if working conditions are favourable to the migrant. But if someone involuntarily ends up in a lower-level job due to low destination country language skills, this may result into a lower satisfaction with various aspects of the job. As an objective outcome, we look at the professional level. If the underlying mechanism runs from language proficiency via professional level (objective outcome) to job suitability and satisfaction (subjective outcomes), then directly measuring the impact of language proficiency on subjective outcomes skips the intermediate step. Therefore, in an additional analysis using the objective information, we first establish the relationship between professional level and the subjective outcomes, and next the relationship between language proficiency and the professional level. To narrow down the scope, we focus on the impact of language proficiency level on the probability of ending up in an unskilled manual job.

\footnotetext{
${ }^{1}$ Migrants in the Netherlands originate from (former) colonies of the Netherlands, like Suriname, who know the Dutch language relatively well, but who often speak their own language among each other, from western countries, with languages that are related to Dutch (like German), and from non-western countries (like Morocco or Asian countries), whose languages are hardly related to the Dutch language.

${ }^{2}$ For instance if lower level jobs allow for more flexibility or less stress.
} 
In measuring the impact of language proficiency on labour market outcomes some econometric issues deserve attention. Our indicator for language proficiency comes from survey information and we need to account for the fact that this is an indicator of an underlying latent language proficiency level. Moreover, if migrants are aware of a possible desirable impact of language proficiency on labour market outcomes, they may invest in language skills in order to improve upon labour market outcomes. This actually may be part of the impact of interest, but what is more important is that there may be unobserved individual specific effects that correlate both with language proficiency and with labour market outcomes.

To allow for these potential sources of correlation, our estimation framework consists of a simultaneous two equations random effects model with an equation for language proficiency and an equation for the labour market outcome of interest. Exploiting the panel nature of our data, we allow for time invariant random effects in both equations with an unrestricted cross equation correlation coefficient. Identification of this correlation comes from observing the same individual in multiple waves, and therefore does not lean on instrumentation. Nevertheless we still need to instrument ${ }^{3}$ language proficiency to address the idiosyncratic correlation between the two equations that we wish to allow for. Instrumentation and the potential endogeneity issue of language proficiency was addressed by Chiswick and Miller (1995) and Dustmann and Van Soest (2001). The former use theoretical exclusions restrictions (family variables affect proficiency but not earnings), while the latter use parental education to instrument proficiency.

We follow a different approach by estimating our model using a variety of instruments to gain insight in the robustness of the outcomes. Perhaps the most convincing instrument is based on a measure of linguistic distance, described by Bakker et al. (2009) in the linguistic literature and applied by Isphording and Otten (2011) in a study of determinants of language proficiency of migrants in Germany. We apply this linguistic distance measure to the available survey information on the language that someone grew up speaking. We allow for a cross effect between this linguistic distance measure and the age at which migration into the Netherlands took place. To check whether the measure of linguistic distance correlates with

\footnotetext{
${ }^{3}$ More precise: identification requires variables that do explain language proficiency but have no direct impact on the labour market outcome.
} 
other distance measures, which may violate the exclusion restriction, we include geographical distance and genetic distance (from Spolaore and Wacziarg, 2009, see also Ashraf and Galor, 2012) in our analysis.

However, linguistic distance is not the only instrumental variable that we use. We also employ survey information about respondents' personality and values as instruments which add to the explanation of language proficiency. Some of the instruments are a priori more convincing candidates than others, but the sheer fact that we provide outcomes for various sets of exclusion restrictions, in addition to the random effects panel specification, allows us to shed light on the robustness of our outcomes and, indeed, shows that our outcomes do not heavily lean on one single exclusion restriction.

Thus, our analysis consists of several steps. First, we analyze the determinants of language proficiency. This step is meant to identify the relevant background characteristics and to shed light on the quality of our language proficiency indicator. Next, we apply the simultaneous two equations model to the subjective labour market outcomes on job suitability and job satisfaction, after which we analyze the professional level. The data come from the LISS panel. We use four waves from the years 2008 through 2011. This survey contains relevant information for our analysis. We can identify the country of birth of a respondent, we have information on the number of years the migrant is residing in the Netherlands, and the language(s) the migrant grew up with, and it contains information about the proficiency of speaking (fluency) and reading (literacy).

A shortcoming of our data is that the period of observation and number of observations are not big enough to set up a completely dynamic model, in which current outcomes depend on past variables for a given individual. Indeed, we are not aware of the existence of such a dynamic framework in the literature. For the moment, such an approach is left for future research, and the desirability of such a framework, if there, also shows helps us thinking about future data requirements.

Results show that the analysis of determinants of language proficiency identifies variables that are in line with determinants discussed in the literature (Chiswick, 2007), which gives confidence in our observed measure of language proficiency. In our analysis of labour market outcomes we find for men a positive relationship between language proficiency and 
satisfaction with the type of work and career (which is quite robust across different exclusion restrictions), and we find that for men language proficiency adds to the match between education/skills and the job. Moreover, men are less likely to end up in a low-skilled manual job if they have a higher proficiency. For women, we do not find any robust effects. There is some evidence for women that a low level of proficiency leads to problems in performing their jobs, but the result is not robust. However, an additional analysis using employment as an outcome variable shows that for women language proficiency may influence selection into employment, whereas for men such a selection effect is absent.

In section 2 we describe the data from the LISS survey. In section 3 we describe the measure for linguistic distance. In section 4 we analyze the determinants of language proficiency. Section 5 presents the results of analyzing the relationship between language proficiency and labour market outcomes.

\section{Data}

Data come from the LISS $^{4}$ panel, a panel survey drawn from the population in the Netherlands, consisting of roughly 5000 households (8000 individuals). ${ }^{5}$ We use four waves for the years 2008 through 2011. ${ }^{6}$ The LISS survey collects information on a great deal of topics, including the household's economic situation (income, assets), work and schooling, religion and ethnicity, and health. Individuals reporting to be born outside the Netherlands are defined as migrants. We exclude individuals born in Belgium as one of the major languages in Belgium is Flemish, similar to Dutch. All Belgian immigrants in the survey have the highest proficiency level according to our survey indicators. In our base sample, we select individuals

\footnotetext{
${ }^{4}$ Longitudinal Internet Studies for the Social Sciences.

${ }^{5}$ A detailed description of the sample selection procedure can be found in Scherpenzeel (2009).

6 The panel started in October 2007 and 2008 was the first complete year of data collection. In 2011, LISS introduced the 'Immigrant Panel'. This is a new panel consisting of "around 2400 individuals, of which 1700 are of non-Dutch origin" (source: LISS. The remaining 700 of Dutch origin serve as a control group). This is not the panel we are using for our current study. Our study uses the regular panel, initiated in 2007, which also contains immigrants. In 2011, these immigrants are still in the regular panel (the 'Immigrant Panel' was newly drawn), but no refreshment was added. The 'Immigrant Panel' provides less details about country or language of origin (the emphasis is on the bigger groups of migrants in terms of country of origin) and also does not contain the same question on language proficiency.
} 
older than 22 and younger than 65 for which the relevant information is observed. ${ }^{7}$ This results in a sample of 1303 individuals-years observations (pooled over the four waves) of 549 different individuals. We use this as our base sample for analyzing the determinants of language proficiency. For the second part of our analysis (the labour market outcomes) we use smaller subsamples, depending on the availability of the information on the outcome variables, which are typically observed for individuals with a job.

As all sample participants, the migrants participating in the survey are drawn from the municipal registers. ${ }^{8}$ The consequence for the selection of migrants is limited since migrants not included in these registers are staying on a so called "short stay visa", ${ }^{9}$ or a period of at most 3 months. These visa are issued to people who are visiting friends or relatives, or are in the Netherlands as a tourist. Everybody else who comes to the Netherlands for more than 3 months, also if work or study is the main reason for migration, needs to be registered at the GBA to receive a residence permit, whether temporary or permanent. ${ }^{10}$ Scherpenzeel (2009) reports that the sample is biased toward households in which at least one adult is capable of understanding the Dutch language ${ }^{11}$ and provides some rough numbers indicating the consequence of this selection: she shows that $3 \%$ of the gross sample (i.e. the addresses initially drawn from GBA) is classified as 'non usable' which includes addresses that are dropped due to language problems, in addition to "among other things, non-existing or noninhabited addresses, companies, long term infirm or disabled respondents." This relatively small percentage shows that the impact on selection into the panel was limited, although once selected in the panel there can be additional implications for, say, item non-response. ${ }^{12}$ The analysis of language proficiency in section 3 will shed more light on the quality of the

\footnotetext{
${ }^{7}$ After the age of 22 , most individuals will have finished their education and are available for the labour market. At the age of 65 people are usually eligible for the state pension. Many Dutch workers will be eligible for some kind of early retirement arrangement, but migrants who move in at a later age than 15 will not have full coverage for the first pillar pension.

${ }^{8}$ Households in the LISS are drawn from the GBA, "Gemeentelijke basisadministratie".

${ }^{9}$ Visum Kort Verblijf.

${ }^{10}$ Drawing from the municipal registers automatically excludes illegal, non-registered, immigrants.

11 The questionnaire is computer based and questions appear in Dutch to respondents. However, questionnaires in English are downloadable from the LISS site. It is not known to what extent respondents make use of this opportunity.

${ }^{12}$ Selection bias would be a more serious problem if we were studying the impact of language proficiency on social exclusion. Here we mainly focus on employed workers who at least must have some contacts in the Dutch society.
} 
data. $^{13}$

Information about fluency and literacy is obtained with two survey questions. The first, for fluency, is:

"When having conversations in Dutch, do you ever have trouble speaking the Dutch language?"14

1. yes, often have trouble/do not speak Dutch ${ }^{15}$

2. yes, sometimes

3. no, never

A similar question is asked for reading:

"When reading newspapers, letters or brochures, do you ever have trouble understanding the Dutch language?"

1. yes, often have trouble/do not speak Dutch

2. yes, sometimes

3. no, never

For our base sample, we selected individuals that show no nonresponse to these two questions, and for which basic characteristics (education level, gender, and the number of years they live in the Netherlands) are observed. ${ }^{16}$

Table 1 contains descriptive statistics for our sample. The first column shows the sample selected on age $(22<$ age $<65)$. The second column shows observations that are more

\footnotetext{
13 No impact of relevant background variables on language proficiency would be found if sample selection were to remove a large share of the sample. However, the analysis in the next section shows that various explanatory variables show a significant impact in the expected direction.

14 The phrasing of the question differs from other surveys known from the literature, where respondents are often asked to report their speaking skills on a scale of 1 to 5 , ranging from very bad to very good. This way of phrasing the question requires the respondent to be aware of what is 'good' or 'bad' as far as speaking the language is concerned. The phrasing of the question in the LISS is implicitly linked to the event of 'having trouble speaking' the language. On the one hand, this gives the respondent a reference point to judge what is good or bad, but on the other hand the outcome of the response may be related to the respondent's situation. Someone in employment, or doing effort to find a job, may respond differently than someone who stays at home and does the housework.

15 A priori, the response in this category may be low for a sample drawn from the municipal registers.

16 Only very few observations are lost by these latter selections.
} 
attached to the labour market (we dropped students, retired, disabled, and housewives). The first line shows information about the country or area of birth. The biggest groups of migrants in the Netherlands originate from Turkey, Morocco, the Dutch Antilles, Suriname, and Indonesia, the latter three being (former) Dutch colonies. ${ }^{17}$ Individuals from other origins are classified into groups. Originally, our idea was to classify respondents into groups of languages that are more or less related to the Dutch language. This is relatively easy to do for most western countries: countries with English as the main language (US, UK, Australia) can be grouped together, countries with Germanic (German and Scandinavian) languages, a language family to which also the Dutch language belongs, can form a group, and Latin languages may be grouped together (French, Italian, Spanish). The German languages are closest to Dutch, followed by English and the Latin languages. But for the remaining countries it becomes increasingly difficult to classify countries by language, firstly because some languages show hardly any relation to languages in other countries, and secondly because for many countries there is no one to one relationship between language and country (for instance, in Africa language may be determined by tribe, rather than by nation). Therefore we end up by classifying the survey respondents in any of the following categories: English speaking, Germanic, Latin, Countries with English as 2nd official language, Asian countries, Middle East, Africa, and Eastern Europe. ${ }^{18}$ To exploit more information about individual countries, we add distance measures, as discussed in the next section. We include measures for linguistic distance (based on the language that someone grew up speaking), geographical distance, and genetic distance.

\footnotetext{
17 Immigration from Turkey started at the end of the 1960-s/beginning of the 1970-s, mostly by male labour migrants. Families followed. Migration from Morocco started somewhat later, from the 1970-s on. Suriname and Indonesia were former Dutch colonies. When Suriname became independent in 1975, a movement of migration to the Netherlands took place. Indonesia became independent in 1948, and a large share of Indonesian migrants is of older age. The Dutch Antilles is somehow still part of the Kingdom of the Netherlands. There is no specific year at which a large group of immigrants entered from the Dutch Antilles, but migration happened throughout the years. Most older Indonesian migrants learned Dutch in their country, but this will not generally hold for the younger generations. The Dutch language is still used in Suriname and the Dutch Antilles, but mainly as an official language. People among each other speak their own language and especially in Suriname different population groups speak different languages. The respondents from the 'other' non-western and western countries originate from a diversity of countries and we somehow need to classify them into larger groups.

18 The category 'Latin language' can be subdivided into western (mainly southern European) and nonwestern (South American) migrants. Migration from Eastern Europe happened more often after the fall of the Berlin wall, and after the admission of some Eastern European countries in the European Union. Also migration from Africa seems to be more recent, after the warfare in several areas.
} 
Table 1 identifies migrants from Turkey and Suriname as the largest groups. Narrowing down the sample to individuals that are more attached to the labour market reduces the shares of migrants of Turkish and Asian origin and increases the share of migrants from Suriname somewhat.

About $57 \%$ of the migrants reports to experience no speaking problems, whereas the share that experiences no reading problems is somewhat higher, 63.2\%. ${ }^{19}$ More detailed descriptives in Table A of the appendix by area of origin shows considerable variation by origin in an intuitively appealing ordering. For instance, $77 \%$ of migrants from a Germanic country report not to experience speaking problems, whereas for migrants from Asia the percentage is 22. The subsample of respondents attached to the labour market shows somewhat better outcomes for the literacy and fluency indicators. Note, though, that also education levels are higher for this subsample.

In our analysis, we use binary indicators for speaking and reading proficiency. These indicators, named 'speak' and 'read', take the value 1 for those who never have problems in speaking or reading, and is zero otherwise. ${ }^{20}$ Thus, we aggregate the two gradations of 'yes' when it comes to having troubles with speaking or reading Dutch.

Respondents are asked whether they speak Dutch at home or an other language, and if the latter holds, they are asked to report this other language. ${ }^{21}$ Around 70 percent of the migrants speak Dutch at home, which is a larger percentage than the percentage of migrants who never experience any troubles in speaking or reading Dutch. This suggests that there

\footnotetext{
${ }^{19}$ For survey respondents from Dutch/Belgian origin these percentages are 92.1 and 90.6, respectively.

${ }^{20}$ Dustmann and Van Soest (2001) discuss the issue of measurement error since in their data (based on a 5 points response scale) they observe the phenomenon that migrants may adjust downward the evaluation of their own fluency the longer they are in the country. We checked whether in our data such a pattern appears as well, by estimating the transition probability of going from value 'speak $=0$ ' in one period to value 'speak $=1$ ' in the next, including the number of years since migration as a regressor. We did a similar regression for the reverse, a transition from 'speak $=1$ ' to 'speak $=0$ '. We found that the number of years since migration has a positive effect on the first transition (an improvement in proficiency), while it has a negative effect on the second transition (a deterioration in proficiency). Thus, unlike Dustman and Van Soest (2001), there is no evidence of a downward adjustment in the evaluation of one's own proficiency.

${ }^{21}$ First, they are asked to choose from Arabic, Berber, German, Frisian, Indonesian, Turkish, Flemish, or 'other language'. If the answer is 'other language', they are asked to explicitly type the name of their language. Surprisingly, there were some Dutch born respondents who answered by saying they were speaking an other language than Dutch and who filled out some local Dutch dialect, that officially is not a language different from Dutch. There were also some respondents who filled out two languages, among which is Dutch. For the Dutch/Belgium born sample, 3.7 percent responds by saying they speak a dialect. The percentage gets smaller if we select on age and labour market attachment.
} 
are people experiencing trouble in speaking Dutch who nevertheless speak Dutch at home. ${ }^{22}$ A further analysis with the information on speaking Dutch at home (appendix, Table B) reveals that speaking Dutch at home is not so heavily influenced by linguistic distance or country of origin. Education and age since migration are more important determinants. Speaking Dutch at home may also be more prevalent among couples of mixed origin.

The remaining variables in our sample are more or less the usual demographic control variables. Couples with children are more prevalent among the subsample of migrants attached to the labour market, whereas the reverse holds for singles. Table 1 also shows the occupational status variable on basis of which the subsample of those attached to the labour market was made. Removing those who are taking care of the housekeeping causes a reduction in the share of women.

Education levels between countries are difficult to compare. Therefore, we only use a broad categorization of education levels where we distinguish four levels.

In the appendix, Table A, we discuss more detailed descriptives by the grouped countries of origin. Among the migrants, there are relatively more respondents with only a primary level of education than among the natives. The fractions of respondents with the highest and lowest level of education show whether a country delivers more lower educated workers or higher educated knowledge workers. Interestingly, the share of low (high) skilled migrants from Turkey and Morocco is relatively high (low) compared to the native Dutch population.

\section{Linguistic distance and the language of origin}

In the previous section we described the construction of area of origin dummies based on the country of birth. The LISS survey provides more information about the language of origin than can be derived from the country of birth. The following question is included in the survey: "Which language or languages did you grow up speaking?" For various reasons, the answer to this question gives us important information. First, we are able to determine the

\footnotetext{
22 The data show that high (low) fluency does not necessarily lead to (not) speaking at home. For the entire sample of migrants, we find that 53 percent reports to have no problems in speaking Dutch and speak Dutch at home; 20 percent reports both to have problems in speaking Dutch and do not speak Dutch at home; 17.9 percent reports to speak Dutch at home, even though they experience problems sometimes; 9.2 percent never experience problems but do not speak Dutch at home.
} 
language of origin, even for countries with no one-to-one correspondence between language and origin. Second, for migrants born in one of the Dutch colonies, we can determine whether they grew up speaking Dutch, an other language, or a combination of Dutch and an other language. For instance, we found that people from Suriname either grew up speaking Sranan Tongo, Hindustani, or Dutch. Third, for migrants who moved to the Netherlands at school age or younger, we can determine whether the migrant grew up speaking Dutch or the language of origin, or possibly both. This way, we can disentangle the impact of age at migration from the impact of growing up speaking Dutch.

Since we cannot include a dummy variable for any language of origin, we seek to construct a measure for linguistic distance based on the survey information. Isphording and Otten (2011) used a measure for linguistic distance, described in Bakker et al. (2009) in an analysis of language proficiency of migrants in Germany with the GSOEP and found that it is a strong predictor for their language proficiency indicator. ${ }^{23}$ The linguistic distance is measured using a lexicostatistical approach. A list of 40 stable elements from a list of words that is commonly used in linguistics ${ }^{24}$ is compared between two languages to determine the distance measure. The distance measure is based on the "minimum total number of additions, deletions, and substitutions of symbols necessary to transform one word into another" (Bakker et al, 2009). This number is normalized by dividing it by the maximum necessary changes (thus, it becomes a fraction). Finally, a correction is made for arbitrary coincidences between words of different languages, based on the combinations of words from the 40 words list with different meaning. ${ }^{25}$ Holman (2011) provides software and a database to compute the distance measure between any pair of languages. ${ }^{26}$ If survey respondents only report one language in which they grew up speaking, the distance measure is based on that unique

\footnotetext{
${ }^{23}$ Adsera and Pytlikova (2012) use an alternative measure of linguistic distance, based on the language tree.

24 The Swadish list, see Bakker et al. (2009).

${ }^{25}$ After this final correction, the resulting number is not necessarily a fraction any longer, but it is unlikely to exceed 1 by much. Holman (2011), expresses it as a 'percentage' by multiplying it by 100 .

${ }^{26}$ To give an impression of the values (expressed in 'percentages'): for German, we have 50.2, for English 63.22, Sranan Tongo (spoken in Suriname) 74.2, Papiamento (spoken at the Antilles) 90.51, Spanish 91.1, Russian 92.2, Standard Arabic 100, Mandarin 100.3, Turkish 102.33. Thus, we see that for languages far away from Dutch, the distance measures are relatively close together (with Spanish remarkably close to Russian), whereas for languages closer to Dutch, like German and English, the differences in the distance measure are relatively far apart. Thus, the distribution of distance measures will be skewed, as also noted by Isphording and Otten, (2011).
} 
language. If the migrant reports both Dutch and a foreign language, we experiment with two values: one based on Dutch (distance is zero) and the other based on the foreign language (see results next section).

We will use linguistic distance as an instrument for language proficiency: we make the assumption that it only affects labour market outcomes via language proficiency. Country dummies for former Dutch colonies and age at migration are not used as exclusion restriction to prevent that linguistic distance would proxy for omitted variables. ${ }^{27}$ However, linguistic distance would not be a valid instrument if it would proxy for other distances between the country of origin and the country of destination that do have a direct effect on labour market outcomes. Chiswick and Miller (2001) include geographic distance as an indicator for language proficiency. We will also include an indicator for geographical distance, based on the shortest distance between the capital cities of the countries. ${ }^{28}$ Spolaore and Wacziarg (2009) and Ashraf and Galor (2012) address the impact of genetic distance and, respectively, genetic diversity, on differences in economic development between countries. If linguistic distance correlates with genetic distance, whereas the latter potentially affects economic outcomes, our exclusion restriction will be violated if we do not correct for genetic distance. Spolaore and Wacziarg (2009) made data on genetic distance available and we use this information in the estimation. ${ }^{29}$

\section{Determinants of fluency and literacy}

Chiswick (2007) discusses the relevant determinants of language proficiency in terms of the 3 E's: exposition, education, and economic incentives. Using our data for migrants in the age

\footnotetext{
${ }^{27}$ In the next section we show that our linguistic distance measure has explanatory power for our language proficiency indicator, next to age at migration and area of origin dummies.

${ }^{28}$ It should be noted that the linguistic distance measure by Bakker et al. (2009) is purely based on a comparison of words in different languages. Geographical distance can be quite different even if linguistic distance is similar (as in the case of the UK and the US).

${ }^{29}$ We refer to appendix in Spolaore and Wacziarg (2009) for all the technical details on measuring genetic distance. For European countries, there are only four different values for the measure of genetic distance, which would be picked up by our area of origin dummies. For countries at larger distance the genetic distance measure actually shows much more variation than the linguistic distance measure, which makes it interesting to see how genetic distance affects outcomes. Ashraf and Galor (2012) explain how genetic diversity spread across the world, leading to a spread of genetic diversity that cannot simply be approximated by geographic distance.
} 
range older than 22 and younger than 65 (Table 1) we analyze the various determinants for our fluency indicator. Results for literacy turned out not to be fundamentally different and are presented in the Appendix, where we also present a sensitivity analysis for the subsample of migrants attached to the labour force.

Table 2 shows Probit regressions results for fluency (dependent variable is 'speak', see Table 1). All presented standard errors allow for correlation in unobserved errors across time for the same individual (clustering). ${ }^{30}$ We gradually add more regressors to gain insight in the differential impact of various determinants of fluency. Starting with the origin dummies, with Asia as a reference group, the coefficient estimates show a ranking that is largely in accordance with the expectations: immigrants from (former) Dutch colonies (Suriname, Indonesia, and Dutch Antilles) have a better fluency, and also immigrants from German/Scandinavian origin, with languages related to Dutch, do relatively well. Immigrants with English and Latin languages follow. For immigrants from the Middle East, Morocco, Eastern Europe, and with English as a second language, there is no evidence that their fluency is better than the reference category Asia. The bottom of Table 2 shows the log-likelihood value and the Pseudo R-squared. The latter indicates that the origin indicator explains about $10 \%$ of the fluency indicator. The origin indicators are area of origin fixed effects that can absorb the impact of linguistic differences, but also the size of the migrants group in the destination country, and other potential differences.

Next, we add to the origin fixed effects the linguistic distance. ${ }^{31}$ We used information about the language someone grew up speaking to assign the value of the linguistic distance, which can be more detailed, or differ, from the information about the country of origin. Survey respondents can report multiple languages in which they grew up speaking, among which can be Dutch. We experimented with two linguistic distance variables. The values of the variables are the same for respondents reporting one language. The first variable (labelled 'Linguistic Distance' in Table 2) is set to Dutch if Dutch is among the languages that

\footnotetext{
30 Note that in this part of the analysis we use a Probit model, rather than a random effects probit model. Since this is a single equation analysis, the gain of adding random effect would be efficiency of the estimator, provided that the random effects structure holds. We rather present the possibly less efficient but more robust probit model with corrected standard errors. Once we present the two equations models in the next section, we allow for random effects, since random effects allow us to identify unobserved individuals specific correlation between proficiency and the economic outcome of interest.

31 Numerically we expressed the linguistic distance as a 'fraction' (see discussion section 3).
} 
someone grew up speaking, while the second variable (labelled 'Linguistic Dist. (foreign)' in the Table) is set to the distance to the foreign language. Table 2 shows that both variables have a significant negative impact on fluency with a coefficient of comparable size. However, adding the first variant increases the R-squared from 0.10 to 0.21 , while for the second the R-squared becomes 0.17 . Therefore, we continued with the first variant. ${ }^{32}$

Note that we include both linguistic distance and dummies for area of origin. We can do that because linguistic distance itself is more refined (for some classes, different countries with different languages are aggregated into the same area of origin, while on the other hand, people from the same country may have grown up speaking a different language). We therefore do not need to exclude a class of from the area of origin dummies. The idea is that the linguistic distance measure picks up the impact of language, while the area of origin dummies proxy for other factors that may also affect economics outcomes (like coming from a western country, race, culture, size of the immigrant population).

Linguistic distance may not be a good exclusion restriction for labour market outcomes if it proxies for other distance measures between the country of origin and the country of destination. In section 3 we discussed the geographic distance and the genetic distance (using data from Spolaore and Wacziarg (2009)) as alternative distance measures. We base this distance information on the country of birth of the migrant and included the distance measure in the regression for fluency. Both indicators have a negative, but insignificant effect on fluency, while the coefficient of the linguistic distance variable is not affected. We nevertheless will keep the variables in the analysis, as they may still affect labour market outcomes, even if they do not affect proficiency.

Adding education (with higher and university education as reference category) shows that migrants with the lowest education level tend to have more problems in speaking Dutch. This is in line with education being one of the three E's affecting language proficiency.

The sixth regression adds the age of migration and its square. Age of migration is computed by subtracting the number of years that the migrant has been in the Netherlands

\footnotetext{
32 Other alternatives we tried were including a dummy variable indicating whether Dutch is among the languages someone grew up speaking and adding linguistic distance squared. The squared effect was not significant, whereas the dummy adds flexibility, but in the final specification, with all variables added, it did not add to the explanation in terms of the R-squared. To avoid the weak instruments problem (see Bound et al. (1995), we do not include the squared effect and the dummy in our final specification.
} 
from the age of the migrant. Chiswick and Miller (2001) also include this variable in their analysis, and predict that age of migration has a negative effect on language proficiency. The Pseudo R-squared and the log-likelihood value both show that the age at migration has a relatively big impact on the explanation of our fluency indicator: adding the age of migration and its square increases the Pseudo R-squared from 0.22 to $0.34 .{ }^{33}$ It is interesting to see that age at migration still has a relatively big impact on language proficiency, given the fact that we have already included information about migrants who grew up speaking Dutch, incorporated in our linguistic distance variable.

So far we included age at migration and its square, but there are good reasons why the impact of linguistic distance may be different for migrants with a different age at migration. In a study with data for the US, Isphording and Sinning (2013) allow for a cross effect of years since migration and linguistic distance. We add a cross effect of age at migration and our preferred linguistic distance measure. In Table 2 we find that the separate coefficient estimates of linguistic distance and the cross effect seem insignificant, while the p-value of the cross effect of linguistic distance and age at migration is just above 0.10 , but if we look at the likelihood ratio test statistic, we see that the cross effect adds significantly to the explanation of language proficiency. Note that age at migration and its square remain significant, even after adding the cross effect of linguistic distance and age at migration. In the next columns of Table 2, once we add age, gender, and household composition, we see that the separate coefficient of the cross effect of linguistic distance and age at migration is significant and negative: this shows that the negative impact of linguistic distance on language proficiency is more important for immigrants who move in at a higher age.

There are some technical issues around the use of linguistic distance as an instrumental variable. If linguistic distance were only based on country of origin, it would fail to predict

\footnotetext{
${ }^{33}$ In order to address the question whether age at migration merely approximates the difference between migrants who entered the Netherlands during youth, and therefore were educated in the Dutch schooling system, and migrants who entered during adulthood we did an analysis with a selected subsample of migrants who entered at a later than 12 (and therefore did not attend primary school in the Netherlands) and another analysis with a subsample of migrants who entered at age older than 18 (and thus did not attend secondary school in the Netherlands). We found a similar pattern as for the entire sample (a significant negative effect of age at migration and a small positive squared effect). The impact of age at migration on the pseudo R-squared is still substantial, but smaller, also because the impact of area of origin has a relatively bigger impact for those who entered at adulthood.
} 
outcomes specific to the individual, as all individuals with the same country of origin would have the same predictor. Note, though, that we combine the measure of linguistic distance with information about the language that someone grew up with. Taking the cross effect of linguistic distance and age at migration, further adds individual specific variation. In our analysis of the impact of language proficiency on economic outcomes, we will do a detailed sensitivity analysis. We will check how sensitive are the estimation results when we only include linguistic distance (and not the cross effect), but also when we include both linguistic distance and the cross effect, and finally, when we include only the cross effect. The results show that the qualitative outcomes are robust to these different choices.

Continuing our analysis, in the next column of Table 2, we add age and gender. Age has a positive effect on fluency, but the coefficient estimates for age at migration do not change much once age is added. ${ }^{34}$ In the literature there is a discussion on whether or not to separate the analysis for men and women, since men and women may have different incentives for learning a language, especially if women are less attached to the labour market. The dummy indicator for female gender is not significant. ${ }^{35}$ Table 2 continues with a regression where we included variables for household composition. Notably the impact of children got attention in the literature: on the one hand, children may stimulate the fluency of parents, as they learn the language quickly at school, while on the other hand, the children may serve as translators for their parents, such that the parents themselves exercise the language less actively. Moreover, there may be a differential impact by gender. We included the number of children, as well as indicators for household type (couples without children, couples with children, lone parents, other households, and singles as reference category). The fluency of lone parents seems to be significantly lower than for other household types. The dummies for other household types are not significant. A likelihood ratio test confirms joint significance of the variables added, but the Pseudo R-squared does not show a large explanatory impact of these five variables on our language fluency indicator. Not reported is a regression which

\footnotetext{
${ }^{34}$ In an additional regression, we also included age squared, but its effects was not significant. Therefore, from now on we only include age.

35 Not reported here are regressions where we included cross effects for female gender and other variables. We included cross effects of female with the indicators Turkish and Moroccan origin, as these countries are dominantly Islamic, and the position of women may be different in these countries. We did not find any significant effects. Later we report on cross effects of gender with indicators for household composition.
} 
includes cross effects of the family indicators with gender. The value of the likelihood ratio test statistic for testing the joint significance of the cross effects with gender is 5.8, indicating that we cannot reject that there are no gender specific household composition effects.

Next we add an indicator for speaking Dutch at home. It is likely that speaking Dutch at home happens more often among couples of mixed origin. Chiswick (2007) notices that exposure to a language, for instance by speaking the language at home, helps in improving upon the fluency. The coefficient of speaking Dutch at home is significant at the $5 \%$ level. ${ }^{36}$

Finally, we included dummies for the degree of urbanization. A priori, the effect of urbanization is not signed: in an urban area migrants may easier meet Dutch speaking people which increases exposure to Dutch, while on the other hand in urban areas there may be a larger concentration of migrants from the same area of origin, which may decrease contacts with the native Dutch. The reference category in the regression is 'not urban'. None of the urban dummies is significant, although it is interesting to note that we spot kind of a U-shaped pattern: migrants in moderately urban areas do worst in terms of speaking fluency, but they do better the more or less urban is their area. Since none of the coefficients is significant, we should be very careful in drawing any conclusions from this result.

Table $\mathrm{C}$ in the appendix shows some sensitivity analyses. The left part shows regression results for the literacy indicator in our sample. The overall picture is the same. Differences are that education has a somewhat more pronounced effect, and that the influence of linguistic distance is smaller. Table A showed that migrants less often report problems with reading than with speaking, while for the native Dutch in the sample it is the other way around. We therefore consider the fluency indicator as the more reliable indicator of proficiency, as it requires more active skills of the migrant. In all the subsequent analyses, we use the fluency

\footnotetext{
${ }^{36}$ If speaking at home is an important determinant of exposure, it may be interesting to see which other variables correlate with the decision to speak at home. Therefore, we ran a probit regression with 'speaking Dutch at home' as the dependent variable. Results are in Table B in the appendix. We see that the ordering of areas of origin found in the fluency regressions, changed for 'speaking Dutch at home'. Especially Turkish migrants are less likely to speak at home. Suriname migrants are more likely to speak at home. For the remaining we do not see a clear ordering of areas of origin, as opposed to the fluency regressions. Linguistic distance has a negative effects while also age at migration has a negative impact and lower educated speak Dutch at home less often. Women speak Dutch at home more often. We also included cross effects of the gender dummy with family composition. These cross effects show that men in couples with children more often speak Dutch at home, but there is also an off-setting effect of the number of children: men speak less often Dutch at home the larger is their number of children.
} 
indicator. The right side of Table $\mathrm{C}$ shows results for fluency, but with a restricted sample of respondents that are attached to the labour market. Results are also comparable to the findings in Table 2. An exception is that we now find a positive impact of the female gender.

\subsection{Additional instruments}

In our analysis of the impact of language proficiency on various economic outcomes, presented in the next section, the linguistic distance measure, based on language that someone grew up speaking, and its cross effect with age at migration, are our main instruments. We will present various sensitivity analyses with different indicators for linguistic distance: we do an analysis using only linguistic distance, and not the cross effect, another analysis using only the cross effect, and an analysis using both linguistic distance and its cross effects with age at migration. Avoiding a weak instrument problem may be an argument of using only the cross effect. We will show that these choices do not affect the qualitative results of our analyses.

But we also want to check how sensitive are our results to the use of a couple of other instrumental variables. Not all instruments that we add may be equally convincing, but it is good to provide a broad range of (combinations) of instruments to see how results are affected. We exploit additional information from the LISS survey as candidates for instrumental variables.

From the LISS survey we selected two answers to statements about personality. The survey question is "How accurately each statement describes you?". Answers can be selected from five response categories in increasing order. The selected statements are "I have a rich vocabulary" and "I am quick to understand things". Table 3 shows the response. ${ }^{37}$ We construct dummy variables for the response categories, and on basis of the response we merged the lower two categories for the vocabulary question and the lower three for the other. The resulting lower categories are the reference categories.

Table 4 shows regression results that includes the variables. ${ }^{38}$ Coefficient estimates are

\footnotetext{
37 The observation number is somewhat lower than our initial sample, due to the fact that different sections of the LISS survey are sent out and responded to in different months of the year.

38 In the regression equations presented in Table 4 we only included the cross effect between linguistic distance and age at migration.
} 
significantly different from zero, showing that respondents confirming to have a rich vocabulary and to be quick to understand things are less likely to have problems in speaking Dutch.

The statement "I have a rich vocabulary" is not (meant to be) about the Dutch language, but if migrant respondents interpret it as such, it may by itself be an indicator of destination language proficiency, rather than a predictor. Therefore, we tried another alternative instrument based on the following statement presented to the respondents: "It is difficult for a foreigner to be accepted in the Netherlands while retaining his/her own culture". Response could take place in five categories, ranging from "fully disagree" to "fully agree".39 The response to the question may indicate the willingness or ability to integrate in the Dutch society. ${ }^{40}$ In the regression in Table 4 we merged the opinions "fully disagree" and "disagree" to one category "disagree". Dummies for the other categories were not different from the base so we omit them all to reduce the weak instruments problem. ${ }^{41}$ We see that respondents who disagree tend to have a higher score on language proficiency. We again see that the Pseudo R2 also is higher than in regression without these instruments.

\section{$5 \quad$ Language proficiency and jobs}

We empirically analyze whether a poor proficiency of the Dutch language may lead to migrants performing jobs which do not match their education and skill level, leading to lower satisfaction. We use subjective information on job suitability and satisfaction (section 5.3) and objective information about professional level (section 5.4).

\footnotetext{
39 We added the category "missing" as we found that response to the politics and values section of the survey was lower for respondents with lower proficiency.

40 We found that migrants from Turkish or Moroccan origin (mostly Islamic), as well as Africans, indicated more often that it was difficult to be accepted in the Netherlands, whereas the opposite holds for migrants from western countries.

41 So it is "disagree" versus the rest.
} 


\subsection{Subjective information on educational match and job satisfac- tion}

The survey contains subjective questions to collect information about the match between education, skills and the job. The first question is about education:

"Please indicate on a scale from 0 to 10 how your highest level of education suits the work that you now perform",

with zero indicating "does not at all suit my work" and ten indicating "suits my work perfectly". A similar question is asked for knowledge and skills:

"Please indicate on a scale from 0 to 10 how your knowledge and skills suit the work you do."

A final question that we use in our analysis is

"Can you indicate on a scale from 0 to 10 whether your knowledge and skills create any problems in fulfilling your position"

with zero indicating "very serious problems" and ten indicating "no problems at all". All these questions are asked to people with a paid job at the moment of the interview.

As far as job satisfaction is concerned, information about the following aspects is collected and used in our analysis:

"How satisfied are you with:
a) your wages or salary"
b) the type of work that you do"
c) your working hours"
d) your career so far"

Respondents could answer by indicating a number in the range of zero to ten, ranging from "not at all satisfied" to "fully satisfied". Table D in the appendix shows sample frequencies of the outcomes, also by gender. 


\subsection{Econometric specification}

The structure of the data collected this way suggests the use of an ordered regression framework. But there are three important issues we need to address. First, in our data we observe an indicator of language proficiency, but we need to acknowledge that the language proficiency itself is a latent variable. Second, unobserved individual specific effects that influence language proficiency may also have an impact on labour market outcomes. Third, we wish to fully exploit the panel nature of our data and control for unobserved individual effects. These issues are combined in the following model specification. Define $l_{i t}^{*}$ as a latent variable indicating language proficiency, whereas $l_{i t}$ is a binary indicator for it (like the indicator 'speak' in our data). Then we may define the equation

$$
l_{i t}^{*}=z_{i t}^{\prime} \beta+m_{i}+\epsilon_{i t} \text { with } l_{i t}=\iota\left(l_{i t} *>0\right)
$$

with $z_{i t}$ a vector of observable characteristics, uncorrelated with $m_{i}$ and $\epsilon_{i t}$, which are individual specific and idiosyncratic (zero mean) random variables, ${ }^{42}$ with $E m_{i}^{2}=\sigma_{m}^{2}$ and $E \epsilon_{i t}^{2}=1$. Let $r_{i t}$ denote one of the job suitability or job satisfaction indicators, and let $r_{i t}^{*}$ be an underlying latent variable.

$$
r_{i t}^{*}=\alpha l_{i t}^{*}+g_{i t}^{\prime} \gamma+\theta_{i}+v_{i t}
$$

with

$$
r_{i t}=j \text { if } c_{j}<r_{i t}^{*} \leq c_{j+1}, j=0, \ldots, 10
$$

with $c_{0}=-\infty$ and $c_{11}=+\infty$. In (2) $g_{i t}$ is a vector of observable characteristics, uncorrelated with $\theta_{i}$ and $v_{i t}$, which are again (zero mean) random variables, with $E \theta_{i}^{2}=\sigma_{\theta}^{2}$ and $E v_{i t}^{2}=1$. We allow for $E m_{i} \theta_{i}=\sigma_{m \theta} \neq 0$ and $E \epsilon_{i t} v_{i t}=\sigma_{\epsilon v} \neq 0$ with corresponding correlation coefficients $\rho_{m \theta}$ and $\rho_{\epsilon v} .{ }^{43}$ The correlation $\rho_{m \theta}$ is identified because of the panel nature of our data. Identification of $\rho_{\epsilon v}$ relies on instrumental variables and exclusion restrictions. As

\footnotetext{
${ }^{42}$ Due to the limited year to year variation in the language proficiency indicators $l_{i t}$ it makes no sense to think about fixed effects estimation.

${ }^{43}$ Note that (2) includes the latent language proficiency $l_{i t}^{*}$, rather than the binary indicator $l_{i t}$, a procedure also followed by Dustmann and Van Soest (2001).
} 
discussed in section 4, our prime instruments is linguistic distance based on the language that someone grew up speaking, and its cross effect with age at migration. We discussed additional instruments that can be used for sensitivity analyses. Equations (1) and (2) will be estimated simultaneously for all labour market outcomes. ${ }^{44}$

\subsection{Results job suitability and satisfaction}

We estimated different model variants. The first specification is a simplification of the model in equation (2): we ignore potential correlation in unobservables between language proficiency and the labour market outcomes, and we simply plug in the fluency indicator $l_{i t}$ at the right hand side, ignoring that this variable is an indicator of an underlying latent language proficiency level. The first two columns of Table 5 show the regression coefficients $(\alpha$ in the notation of equation (2)) for this model, which is labelled as the 'naive model'. ${ }^{45}$ The model is estimated for all observations, men and women pooled, as well as for men and women separately. In the first column we did not include age at migration among the regressors and the results show evidence of positive correlations between the proficiency indicator and the job suitability measures, notably for men. We also find a positive correlation between the proficiency indicator and satisfaction, again notably for men and strongest for satisfaction with work type and career. However, excluding age at migration is not a legitimate exclusion restriction as, in general, this variable is very likely to influence labour market outcomes, and once we add age at migration to the naive model (2nd column of Table 5) significance of the language proficiency indicator largely disappears. Some evidence remains that women with a higher fluency experience less problems in performing their job.

From now on in all the subsequent specifications age at migration and its square are included among the regressors. While discussing the model in (2) and (1) we argued that it is important to correct for correlation in unobservables and that the variable that we observe for fluency is just an indicator of an underlying latent proficiency level.

\footnotetext{
44 A simpler alternative is to first estimate equation (1) and use first stage estimates to estimate model (2), conditional on the errors of (1). The overall fit will be worse, though, and standard errors of the second stage still need to be corrected for the first stage.

${ }^{45}$ For reasons of conciseness we do not display the complete regression results. Table E in the appendix present the full regression results for the variant in which men and women are pooled, including the age at migration.
} 
The subsequent results in Table 5 are obtained with the simultaneous equations model. To check the robustness of the results, we estimated the simultaneous equations model for different combinations of instrument, and we estimated variants with and without random effects. Identification of correlation in random effects between the language proficiency and labour market outcomes comes from the panel nature of our data. This means that the variant without random effects leans more heavily on the exclusion restrictions and the instruments. We present estimates with four sets of instruments. The first contains the cross effect of linguistic distance and age at migration, ${ }^{46}$ the next adds the responses to the statements about having a rich vocabulary and being quick to understand things, the third replaces the statement on having a rich vocabulary by the statement about the difficulty to be accepted as a foreigner, whereas in the final specification we drop the important information on linguistic distance, retaining the instruments based on the statements of having a rich vocabulary and being quick to understand things. By presenting results with several combinations of instruments we aim to check for the robustness of the outcomes.

Table 5 again shows the coefficient estimate of parameter $\alpha$ in (2). The Appendix contains Tables with the complete regression results for equation (2) and the coefficients of the error structure. ${ }^{47}$ All these equations are estimated simultaneously with equation (1). For reasons of conciseness we omitted results for equation (1) since we have already discussed the results of determinants of language proficiency in section $4 .{ }^{48}$ The Tables in the Appendix show the complete set of variables that are included in the equations. To minimize the possibility of measuring a spurious effect of language proficiency on labour market outcomes, we include the country of birth fixed effects, ${ }^{49}$ we include the measures for geographic and genetic

\footnotetext{
46 Table $\mathrm{F}$ presents results with linguistic distance, instead of the cross effects of linguistic distance and age at migration, while Table $\mathrm{G}$ presents results with both linguistic distance and the cross effect of linguistic distance and age at migration. The qualitative outcomes are robust to these choices.

47 Tables $\mathrm{H}$ through $\mathrm{M}$ shows the estimation results for pooled data, by gender, without and with random effects, for the variant where the cross effect of linguistic distance and age at migration is used as an instrument. For reasons of conciseness, we do not show complete results for all different instruments, but we show the coefficient of interest in Table 5. We also exclude results for the language proficiency equation, since they are not fundamentally different from the results discussed in section 4 .

48 Another difference between the estimates without and with random effects is that the model without random effects the language proficiency equation is completely gender specific, whereas in the random effects estimation we pooled men and women (like in the analysis in section 4).

${ }^{49}$ A higher level of aggregation of categories was used, since we are estimating with fewer observations than in section 4: middle east and English as a second language were merged to the Asian reference group, and we do not make a distinction between Latin western and non-western countries, on basis of the results of section
} 
distance, age at migration and its square, and variables for household composition. Thus, excluded are the instruments listed in Table 5, together with the variable dutch spoken at home..$^{50}$

Robust among all estimation results obtained with different instruments is the coefficient estimate of fluency on satisfaction with work type, suggesting that a higher fluency level leads to job types with a higher level of satisfaction. Separate estimation for men and women show that this effect is attributed to men. Estimates of fluency on the satisfaction with career and the fit of skills to work lose precision when the linguistic distance variable is dropped from the instrument set (see final two columns of Table 5), but they still show a $10 \%$ significant impact for men. A positive coefficient estimate of language proficiency on the fit between education and work is found for men as long as the linguistic distance measure is included. The outcome variable that shows most variation across instrument sets is the response to the statement that there are no problems with knowledge and skills in performing the current job. For women we find a positive impact of language proficiency on this statement for the second through fourth set of instruments, whereas an insignificant negative effect is found for the first set.

In conclusion we can say that the simultaneous models notably find effects of fluency for men, especially for satisfaction with work type, satisfaction with career, and the fit between ability and work. A positive effect of fluency for men is also found for the fit between education and work, as long as linguistic distance is included as an instrument. Results (not exposed here) with linguistic distance as an instrument were also robust to a more flexible specification with linguistic distance, its square, and a separate dummy variable for whether Dutch was among the language(s) someone grew up with. Results were also robust to more flexible specifications in age at migration: we added dummy variables for age at migration below six (meaning that the migrant followed primary and subsequent education in the Netherlands), age at migration below 12 (meaning that secondary and subsequent education was followed in the Netherlands), and age at migration below 18. Apparently the quadratic in age at migration was flexible enough.

4. We also aggregated family composition by including a dummy for couples versus the remaining household type, as section 4 showed little impact of family composition. The number of children is maintained.

${ }^{50}$ Results were not sensitive to the inclusion or exclusion of the variable Dutch spoken at home. 


\subsection{Language proficiency and professional level}

The analysis so far considered the direct effect of destination language proficiency on subjective outcomes of job satisfaction and indicators for job suitability, and we notably found a robust effect of fluency on the satisfaction with the type of work. The type of work may be related to the professional level of the job, which is a more objective measure of job type. We do an analysis in two steps: we first check how the subjective satisfaction and suitability indicators are related to professional level by including professional levels in ordered probit regressions for the satisfaction and suitability indicators. Next, we analyze the impact of language proficiency on the professional level. Since basically anybody is able to perform semi- or unskilled manual work, irrespective of the education, we narrow down the analysis to the question whether migrants with a lower language proficiency level are more likely to end up in a manual job. In the analysis we will again allow for unobservable correlation between proficiency and the probability to end up in such a job.

Table $\mathrm{O}$ in the appendix shows the various professional levels that are distinguished in the LISS questionnaire. We show sample percentages, both for native Dutch and for migrants, in the age range 22 to 65 , for which also the language proficiency indicator is observed. At the top of the labour market, we see a relatively (compared to the natives) high representation of migrants in higher academic professions. ${ }^{51}$ It is likely that for this group, Dutch language skills are of minor importance for their job characteristics, especially if they work at universities or multinational companies. But the higher educated is a small and specific group, also among the natives. Among higher supervisory professions, the migrants show smaller sample frequencies than the Dutch, and actually for almost all intermediate level professions, ranging from intermediate academic down to skilled and supervisory manual work, we see lower sample frequencies of migrants, compared to the native Dutch. The reverse holds for the lower three categories in the table, consisting of semi-skilled and unskilled manual work and agrarian professions. Adding them together, we see a much larger representation of migrants among these professional levels. In general, there will be a strong correlation between education level and professional level, so it is imaginable that part of the higher prevalence of

\footnotetext{
${ }^{51}$ Note, though, that the Table shows unweighted sample frequencies, so we should be careful in using them for drawing conclusions for the population as a whole. Population weights are not provided by LISS.
} 
migrants among manual workers can be attributed to differences in educational attainment. But language proficiency may also be a determinant.

In the first step the dummy variables for the professional levels were included in an ordered probit analysis of job satisfaction and job suitability, taking the semi-skilled, unskilled manual work, and agrarian professions as one reference category. Tables $\mathrm{P}$ through $\mathrm{R}$ in the Appendix show the estimation results (for both genders pooled, and men and women separately). For satisfaction with career and satisfaction with work time we see that, both for men and for women, most professional levels lead to a higher satisfaction than the manual reference category. We also find a better fit of education and the job, and of knowledge and skills and the job if the professional level is higher than manual. For men, we do not find much effect of professional level on satisfaction with wage, except that migrants with a higher academic profession are more satisfied with their wage than migrants with manual professions. For women we find a somewhat stronger relation between professional level and satisfaction with wage. For men, we find no relation between the professional level and satisfaction with work time, whereas women with an intermediate professional level seem to be more satisfied than manual workers. For men we do not find that migrants with a higher professional level have more or less problems in performing their job than migrants with a manual profession, whereas women with a higher academic profession seem to experience more problems in performing their job than women in manual professions. Over all, the impression is that if there is any relation between job satisfaction and professional level, migrants in manual jobs are less satisfied.

The second step is to analyze whether there is a relationship between language proficiency and having a manual profession. Also in carrying out this analysis, it is important to correct for possible endogeneity and correlation in unobservables: the information about Dutch language proficiency may proxy for other skills and abilities of the migrant that influence the probability of ending up in a manual profession.

Table 6 shows the estimation results. ${ }^{52}$ The table shows univariate regressions, where the indicator 'speak' is simply plugged in among the right hand side variables, both ignoring that it is an indicator of an underlying latent proficiency level and ignoring possible correlation

\footnotetext{
${ }^{52}$ For the simultaneous equations, we again omit results for the language proficiency equation.
} 
in unobservables. The simultaneous equations estimates are obtained by estimating a two equations system, conform the equations (2) and (1), with the only difference that now we have a binary indicator as a labour market outcome, rather than a ordered outcome. ${ }^{53}$ Table 6 present results in which we used the cross effect of linguistic distance and age at migration an instrument (along with Dutch spoken at home). ${ }^{54}$ The univariate model shows a negative parameter estimate of fluency in the equation for the probability of having a manual job. Estimation by gender shows that this effect is attributed to men. In the simultaneous estimation the parameter estimate becomes less precise, but is still significant at the $10 \%$ level. Moreover, we find that the correlation coefficient between the equations for language proficiency and the probability of ending up in a manual job, $\rho$ is not significantly different from zero. Therefore, we also estimated the model with $\rho$ restricted to zero ${ }^{55}$ and found that the in the parameter of fluency became more precise (significantly different from zero at the $5 \%$ level) whereas, moreover, the likelihood ratio test statistic for testing the hypothesis $\rho=0$ took the value 0.86 (in the estimation for men), such that the null hypothesis is not rejected.

For women, the simultaneous equation model shows a $10 \%$ significant effect, but as opposed to men, this effect disappears when alternative instruments are used. Thus, for women we do not find a robust effect.

In conclusion we may say that at the least we find a negative correlation between the probability of ending up in a manual job for men only.

\footnotetext{
53 We do not present random effects estimates, exploiting the panel nature. The wave to wave within individual variation in manual work turned out to be so small that it is not possible to identify random effects. The variance of the random effect in the manual work equation, which also measures the within individual correlation across time, grew very large during the maximization procedure.

${ }^{54}$ In an earlier version we presented results with only our linguistic distance measure as an instrument. This did not lead to basically different results. Results where we added the other instruments showed a more precise parameter estimate for fluency for men, but may be less plausible as exclusion restriction, since education is an important determinant of ending up in a manual job, and the regressions in Table 4 showed some evidence of collinearity between education and the other instruments. For women, results are not robust for different instruments.

55 Note that this is different from the univariate estimates in Table 6 , because with $\rho$ equal to zero we still allow for the latent nature of language proficiency.
} 


\subsection{Reason for different outcomes by gender?}

The previous analyses showed that, both for subjective and objective measures of job level outcomes, we mainly found an impact of language proficiency for men, but not for women. Since in general, labour market participation rates for men are higher than for women, we did an additional analysis to check whether there is a difference between men and women as far as the impact of fluency on selection into employment is concerned. We did an analysis with employment as the outcome variable, both for a full sample (i.e. measuring employment versus non-employment) and a sample of individuals attached to the labour market (i.e. measuring employment versus unemployed participants). For men we did not find an impact of language proficiency on employment for any sample. ${ }^{56}$ For women, we found a positive impact on employment for both subsamples if we estimate an employment equation simultaneously with an equation for proficiency. ${ }^{57}$ Thus, it seems that for women language proficiency plays a more pronounced role in selection into employment, so once selected into employment proficiency does not have an additional impact on job level outcomes. Men seek to enter employment, irrespective of their language proficiency, and within employment outcomes for job level seem to move together with proficiency.

\section{Conclusions}

We found that a higher Dutch language proficiency leads to a higher degree of satisfaction with the type of work and career for male workers. We find that this result is robust for different combinations of instruments, while we also allow for time invariant individual random effects. In addition, we found that male workers with a lower Dutch proficiency have a higher probability of ending up in a manual job. For women, we do not find (robust) effects. However, it seems that women are affected by language proficiency through the selection into the labour market.

In the literature, the emphasis is on the impact of language proficiency on wages. One of

\footnotetext{
56 For reasons of conciseness we do not show any additional tables results.

57 When we estimated a single equation for employment, including the binary fluency indicator at the right hand side, thereby ignoring simultaneity and measurement issues, we found a positive impact on employment (versus non-employment), but no effect of employment versus unemployed participants.
} 
the possible underlying mechanisms for finding lower wages for less proficient migrants can be the selection of migrants with a lower proficiency in the destination language into jobs of a less favourable type. Our evidence shows that such a channel can be important. Indeed, we do not find any evidence of destination language proficiency on the satisfaction with the wage level, possibly indicating that type of work and career paths may be of greater concern to migrants than merely the wage level.

A labour market situation where migrants work at the right place, but receive lower wages due to a lower proficiency level of the destination language, is inherently different from a labour market situation where migrants work below their level, and therefore receive a lower reward. In the first case, acquiring language skills may be sufficient to grow into their job, while in the second case also the friction of working in the wrong place needs to be overcome. Although this may stimulate migrants to acquire a higher level of destination language skills if the migrant is aware of this mechanism, not receiving satisfactory job offers may have a discouraging effect as well. Moreover, in the first case the migrant and the employer may agree on a programme for increasing language skills, whereas for a migrant working at wrong place for the wrong employer, there a may be a role for government policy to increase matching efficiency at the labour market.

\section{References}

Adsera, A, and M. Pytlikova (2012), The role of language in shaping international migration, Norface Migration Discussion Paper No. 2012-14.

Ashraf, Q. and O. Galor (2012), The "Out of Africa" hypothesis, human genetic diversity, and comparative Economic development, working paper.

Bakker, B, C.H. Brown, P. Brown, D. Egorov, A. Grant, E.W. Holman, R. Mailhammer, A. Müller, V. Velupillai, S. Wichman (2009), Adding typology to lexicostatistics: a combined approach to language classification, Linguistic Typology, Vol. 13, nr. 1, pp. 169-181.

Bound, D., J.A. Jaeger, and R.M. Baker (1995), Problems with instrumental 
variables estimation when the correlation between the instruments and the endogenous explanatory variable is weak, Journal of the American Statistical Association, Vol. 90, no. 430, pp. 443-450.

Chevalier, A. (2003), Measuring overeducation, Economica, Vol. 70, pp. 509-531.

Chiswick, B.R. (2007), The Economics of Language for Immigrants: An Introduction and Overview, Julian Simon Lecture Series, IZA, Bonn.

Chiswick, B.R, and P.W. Miller (1995), The Endogeneity between Language and Earnings: International Analyses, Journal of Labor Economics, Vol. 123, No. 2, pp. 246-288.

Chiswick, B.R, and P.W. Miller (2001), A Model of Destination-Language Acquisition: Application to Male Immigrants in Canada, Demography, Vol. 38, No. 3, pp. 391-409.

Chiswick, B.R. and P.W. Miller (2011), Negative and positive assimilation, skill transferability, and linguistic distance, IZA Discussion Paper No. 5420.

Dustmann, C. (1994), Speaking Fluency, Writing Fluency and Earnings of Migrants, Journal of Population Economics, Vol. 7, pp. 133-156.

Dustmann, C, and F. Fabbri (2003), Language proficiency and labour market performance of immigrants on the UK, Economic Journal, Vol. 113, No. 489, pp. 695-717.

Dustmann, C, and A. van Soest (2001), Language Fluency and Earnings: Estimation with Misclassified Language Indicators, The Review of Economics and Statistics, Vol. 83, No. 4, pp. 663-674.

Gonzales, P.S. (2010), The impact of education and host language skills on the labor market outcomes of immigrants in Spain, Ivestigaciones de Economia de la Educacion 5, pp. 798-824.

Holman, E.W. (2011), Programs for calculating ASJP distance matrices (version 2.1).

http://email.eva.mpg.de/ wichmann/software.htm 
http://email.eva.mpg.de/ wichmann/listss15.zip

Holman, E.W, S. Wichmann, C.H. Brown, V. Velupillai, A. Müller, P. Brown, and D. Bakker (2008), Explorations in automatic language comparison. Folia Linguistica, Vol. 42, pp. 331-354.

Isphording, I.E, and S. Otten (2011), Linguistic distance and the language fluency of immigrants, Ruhr Economic Papers \# 274

Isphording, I.E, and M. Sinning (2013), The returns to language skills in the US labour market, IZA, Bonn.

Mavromaras, K., McGuinnes, S., O'Leary, N., Sloane, P., and Wei, Z. (2010), Job mismatches and labour market outcomes: Panel evidence on Australian university graduates, National Institute of Labour Studies, Flinders University, Working Paper No. 163.

Scherpenzeel, A. (2009), Start of the LISS panel: Sample and recruitment of probability-based internet panel, CentERdata, Tilburg.

Spolaore, E. and R. Wacziarg (2009), The diffusion of development, Quarterly Journal of Economics, Vol. 124, No. 2, pp. 469-529.

\section{A Descriptive statistics by ethnic group}

Table A shows some descriptives by ethnic group. We focus on the table selected on the basis of age, shown in the second pane of Table A. The first two lines compare the native Dutch/Belgium with the entire group of migrants. Among the native Dutch/Belgium, the percentages of respondents that report no problems in speaking and reading Dutch are 92 and 90. For the migrants, these percentages are much lower, 57 and 63. Remarkable is that for the foreign born the percentage reporting no problems in reading is higher than that for speaking, possibly indicating that reading is more like a passive activity in which the reader can determine his or her own pace. There is considerable heterogeneity in the responses depending on the group of origin. The ranking is in line with the expectation: people from former Dutch colonies report relatively often to have no problems with speaking. For 
Suriname, Indonesia, and the Dutch Antilles the percentages are 85, 78, and 68. Among people German origin, whose language belongs to the same family as Dutch, 78 percent reports not to experience any speaking problems. For respondents with English and Latin languages of origin the speaking performance is still a little above the average for migrants (59 per cent without any speaking problems for both groups). People from Asia experience speaking problems most often: only 21 percent reports no problems. Below average is also the speaking performance of the Turkish, Moroccan, people from countries in which English is a 2nd language, Eastern Europe, and Africa, with respective percentages of 44, 42, 41, 44, and 50 for the absence of speaking problems. People from the Middle East report in only 31 percent of the cases to have no speaking problems. People from Indonesia, Germany, and other western countries report to only belong to the Dutch population more often than the average migrant. People from Turkey, Suriname, and Asia most often report to belong to an other population group than the Dutch. People from Morocco, and the Dutch Antilles relatively often report that they belong both to the Dutch population and to another population. People from (former) Dutch colonies relatively often only have the Dutch nationality. Relatively few of the people from Turkey, English and Latin speaking countries report to have only the Dutch nationality. People from Turkey, Morocco, and the Middle East relatively often report to have both the Dutch nationality and an other nationality. It is also interesting to look at the lowest and highest education level by origin. Do immigrants mainly have education levels, or are they highly educated knowledge workers? For some groups, we see an over-representation of low educated people, compared to the Dutch respondents. The percentage of low educated is especially high for the Turkish and Moroccan group. Whereas only 6 percent of the Dutch report to belong to the lowest education group, the percentages are 27 and 30 for the Turkish and Moroccan. At the same time, the percentages of highly educated are relatively low for these groups. Among the Dutch 34 percent is highly educated, whereas these percentages are 13 and 16 for immigrants from Turkey and Morocco. Some groups show a higher percentage of lower educated than the Dutch, but the percentages of highly educated is comparable to the Dutch. This holds for immigrants from Suriname, people with an Latin language, and English as a second language. People from German countries and Asia report both a lower percentage of low educated and a higher percentage of 
highly educated. Also people from English speaking countries, the Middle East and Eastern Europe show a fairly large percentage of higher educated, but their share of lower educated is somewhat higher compared to the Dutch. If we interpret membership of a sports-club or a cultural club as an indicator of social integration, then we see that immigrants from western countries are relatively often a member of a sports-club. Notably people from Turkey and the Middle East are underrepresented as far as membership of a sports-club is concerned, followed by migrants from Indonesia, Africa, Morocco, the Dutch Antilles and Asia. People from English speaking countries, Morocco, and Africa, are relatively often a member of a cultural club, people from Turkey, the Dutch Antilles, Eastern Europe, and Indonesia are underrepresented. 
Table 1: Sample of Migrants

Sample percentages and means of pooled sample

\begin{tabular}{|c|c|c|}
\hline Variable & $22<$ age $<65$ & $\begin{array}{l}\text { Attached to } \\
\text { lab. market } \\
N T=943\end{array}$ \\
\hline \multicolumn{3}{|l|}{ Origin (language group/area) } \\
\hline Turkey & 12.2 & 11.0 \\
\hline Morocco & 7.6 & 7.0 \\
\hline Dutch Antilles & 9.3 & 9.2 \\
\hline Suriname & 11.2 & 13.0 \\
\hline Indonesia & 5.5 & 5.5 \\
\hline German/Scandinavian (language area) & 9.7 & 9.1 \\
\hline English (language area) & 8.0 & 8.1 \\
\hline Latin languages & 10.2 & 10.4 \\
\hline English as official (2nd) language & 3.6 & 3.8 \\
\hline Asia & 4.6 & 3.9 \\
\hline African & 3.5 & 3.9 \\
\hline Eastern Europe & 9.4 & 9.2 \\
\hline Middle East & 5.1 & 5.7 \\
\hline \multicolumn{3}{|l|}{ Troubles speaking Dutch? } \\
\hline yes, often/don't speak Dutch & 4.4 & 3.6 \\
\hline yes, sometimes & 38.6 & 36.9 \\
\hline no, never & 57.0 & 59.5 \\
\hline \multicolumn{3}{|l|}{ Trouble understanding reading? } \\
\hline yes, often/don't speak Dutch & 4.4 & 3.7 \\
\hline yes, sometimes & 32.8 & 30.3 \\
\hline no, never & 63.2 & 66.0 \\
\hline Speak (never problems) & 57.0 & 59.5 \\
\hline Read (never problems) & 63.2 & 66.0 \\
\hline \multicolumn{3}{|l|}{ Speak Dutch at home or other language? } \\
\hline Dutch at home & 68.9 & 72.1 \\
\hline Dutch dialect & 0.5 & 0.4 \\
\hline Two languages & 0.4 & 0.1 \\
\hline Female & 58.0 & 50.2 \\
\hline \multirow[t]{2}{*}{ Age (mean, std) } & 43.0 & 41.8 \\
\hline & $(10.6)$ & $(9.4)$ \\
\hline
\end{tabular}


Table 1 (continued): Sample of Migrants

Sample percentages and means of pooled sample

\begin{tabular}{|c|c|c|}
\hline Variable & $22<$ age $<65$ & $\begin{array}{l}\text { Attached to } \\
\text { lab. market }\end{array}$ \\
\hline Observations: & $N T=1303$ & $N T=943$ \\
\hline \multicolumn{3}{|l|}{ Household type } \\
\hline Single & 16.4 & 17.4 \\
\hline Couple without children & 23.9 & 20.6 \\
\hline Couple with children & 47.4 & 49.8 \\
\hline Lone parent & 10.9 & 10.6 \\
\hline Other household type & 1.5 & 1.6 \\
\hline \multirow[t]{2}{*}{ Number of household members (mean, std) } & 2.9 & 2.9 \\
\hline & $(1.3)$ & $(1.3)$ \\
\hline \multirow[t]{2}{*}{ Number of children (mean, std) } & 1.1 & 1.1 \\
\hline & $(1.1)$ & $(1.0)$ \\
\hline Has partner & 71.2 & 70.4 \\
\hline \multicolumn{3}{|l|}{ Urbanisation } \\
\hline Extremely urban & 26.0 & 25.7 \\
\hline Very urban & 33.7 & 34.2 \\
\hline Moderately urban & 23.0 & 24.5 \\
\hline Slightly urban & 12.2 & 10.4 \\
\hline Not urban & 5.0 & 5.2 \\
\hline \multicolumn{3}{|l|}{ Occupational status } \\
\hline In paid employment & 57.2 & 79.8 \\
\hline Works/assists in family business & 1.5 & 2.0 \\
\hline Autonomous professional, freel, self-empl. & 4.4 & 6.0 \\
\hline Job seeker following job loss & 5.5 & 7.6 \\
\hline First time job seeker & 1.2 & 1.9 \\
\hline Exempted from job seeking following job & 1.0 & \\
\hline Attends school or is studying & 4.5 & \\
\hline Takes care of the housekeeping & 11.8 & \\
\hline Is pensioner, [voluntary] early retirem & 3.8 & \\
\hline Has (partial) work disability & 5.8 & \\
\hline Performs unpaid work while retaining ben. & 0.6 & 0.9 \\
\hline Performs voluntary work & 1.3 & 1.8 \\
\hline Does something else & 1.2 & \\
\hline Is too young to have an occupation & 0.1 & \\
\hline \multicolumn{3}{|l|}{ Education level } \\
\hline Primary education & 12.7 & 9.5 \\
\hline Lower vocational/professional training & 20.3 & 17.7 \\
\hline Higher sec and middle voc/prof training & 32.8 & 34.9 \\
\hline Higher voc/prof training, university & 34.2 & 37.9 \\
\hline
\end{tabular}


Table 2: Probit regressions speaking fluency for sample of migrants, $22<$ age $<65, N T=1303$

\begin{tabular}{|c|c|c|c|c|c|c|c|c|}
\hline Variable & Coef. & Std. & Coef. & Std. & Coef. & Std. & Coef. & Std. \\
\hline Turkey & $0.68^{*}$ & 0.36 & $1.08^{* *}$ & 0.39 & $0.98^{* *}$ & 0.34 & $0.82^{*}$ & 0.43 \\
\hline Moroccan & 0.51 & 0.37 & $0.69^{*}$ & 0.41 & $0.79^{* *}$ & 0.36 & 0.41 & 0.48 \\
\hline Dutch Antilles & $1.20^{* *}$ & 0.37 & $0.97 * *$ & 0.40 & $1.12^{* *}$ & 0.35 & $0.93^{* *}$ & 0.40 \\
\hline Suriname & $1.85^{* *}$ & 0.38 & $1.28^{* *}$ & 0.42 & $1.45^{* *}$ & 0.39 & $1.20^{* *}$ & 0.46 \\
\hline Indonesia & $1.55^{* *}$ & 0.42 & $1.01^{* *}$ & 0.45 & $0.97^{* *}$ & 0.45 & $1.11^{* *}$ & 0.45 \\
\hline German/Scand. & $1.53^{* *}$ & 0.38 & $1.32^{* *}$ & 0.41 & $0.95^{* *}$ & 0.38 & $0.97^{*}$ & 0.52 \\
\hline English & $1.00^{* *}$ & 0.38 & $0.94^{* *}$ & 0.40 & 0.61 & 0.37 & 0.69 & 0.48 \\
\hline Latin, western & $1.06^{* *}$ & 0.39 & $1.51^{* *}$ & 0.42 & $1.17^{* *}$ & 0.38 & $1.20^{* *}$ & 0.51 \\
\hline Latin, nonwestern & $1.06^{* *}$ & 0.38 & $1.20^{* *}$ & 0.42 & $0.78^{* *}$ & 0.39 & $1.21^{* *}$ & 0.45 \\
\hline English 2nd lang. & 0.60 & 0.44 & 0.45 & 0.47 & 0.31 & 0.38 & 0.43 & 0.47 \\
\hline Africa & $0.73^{*}$ & 0.44 & $0.99^{*}$ & 0.51 & 0.57 & 0.47 & $0.90^{*}$ & 0.53 \\
\hline Eastern Europe & $0.62^{*}$ & 0.37 & $1.09^{* *}$ & 0.40 & $0.74^{* *}$ & 0.35 & 0.78 & 0.49 \\
\hline Middle East & 0.34 & 0.40 & $0.78^{*}$ & 0.43 & 0.45 & 0.38 & 0.56 & 0.49 \\
\hline Linguistic Distance & & & $-1.41^{* *}$ & 0.15 & & & $-1.41^{* *}$ & 0.15 \\
\hline Linguistic Dist. (foreign) & & & & & $-1.47^{* *}$ & 0.23 & & \\
\hline \multicolumn{9}{|l|}{ Ling. Dist. x Age at Migr. } \\
\hline Geographic distance & & & & & & & -0.04 & 0.03 \\
\hline Genetic distance & & & & & & & -0.23 & 2.11 \\
\hline \multicolumn{9}{|l|}{ Prim. Education } \\
\hline \multicolumn{9}{|l|}{ Lower voc./prof. } \\
\hline \multicolumn{9}{|l|}{ Higher sec./middle voc. } \\
\hline \multicolumn{9}{|l|}{ Age at migration } \\
\hline \multicolumn{9}{|l|}{ Sqr. Of age at migr. } \\
\hline \multicolumn{9}{|l|}{ Age } \\
\hline \multicolumn{9}{|l|}{ Female } \\
\hline \multicolumn{9}{|l|}{ \# Children } \\
\hline \multicolumn{9}{|l|}{ couple without children } \\
\hline \multicolumn{9}{|l|}{ Couple with children } \\
\hline \multicolumn{9}{|l|}{ Lone parent } \\
\hline \multicolumn{9}{|l|}{ Other household } \\
\hline \multicolumn{9}{|l|}{ Speak Dutch at home } \\
\hline \multicolumn{9}{|l|}{ Extremely urban } \\
\hline \multicolumn{9}{|l|}{ Very urban } \\
\hline \multicolumn{9}{|l|}{$\begin{array}{l}\text { moderately urban } \\
\text { slightly urban }\end{array}$} \\
\hline Intercept & $-0.78^{* *}$ & 0.32 & -0.12 & 0.37 & 0.40 & 0.37 & 0.26 & 0.50 \\
\hline Likelihood Value & -800.7 & & -702.3 & & -738.3 & & -700.7 & \\
\hline Pseudo R2 & 0.10 & & 0.21 & & 0.17 & & 0.21 & \\
\hline $\begin{array}{l}\text { Reference categories dummy } \\
\text { Not urban; Both Dutch ar } \\
* * / * \text { : significant at } 5 / 10 \%\end{array}$ & $\begin{array}{l}\text { iables: } \\
\text { her nati } \\
\text {; standa }\end{array}$ & ; H & $\begin{array}{l}\text { er profes } \\
\text { oth Dutc } \\
\text { adjusted }\end{array}$ & 11 & $\begin{array}{l}\text { ocational } \\
\text { ther popt } \\
\text { tering. }\end{array}$ & ain & $\begin{array}{l}\text { universi } \\
\text { oup. }\end{array}$ & ingle; \\
\hline
\end{tabular}


Table 2: Probit regressions speaking fluency for sample of migrants (continued) $22<$ age $<65, N T=1303$

\begin{tabular}{|c|c|c|c|c|c|c|c|c|}
\hline Variable & Coef. & Std. & Coef. & Std. & Coef. & Std. & Coef. & Std. \\
\hline Turkey & $0.94^{* *}$ & 0.44 & 0.35 & 0.37 & 0.31 & 0.37 & 0.25 & 0.37 \\
\hline Moroccan & 0.51 & 0.48 & 0.26 & 0.40 & 0.25 & 0.41 & 0.23 & 0.41 \\
\hline Dutch Antilles & $1.01^{* *}$ & 0.41 & $1.37 * *$ & 0.33 & $1.33^{* *}$ & 0.34 & $1.32^{* *}$ & 0.34 \\
\hline Suriname & $1.27^{* *}$ & 0.46 & $1.48^{* *}$ & 0.39 & $1.42^{* *}$ & 0.39 & $1.43^{* *}$ & 0.39 \\
\hline Indonesia & $1.16^{* *}$ & 0.45 & $0.81 * *$ & 0.38 & $0.84^{* *}$ & 0.39 & $0.89 * *$ & 0.39 \\
\hline German/Scand. & $0.92^{*}$ & 0.52 & $1.03^{* *}$ & 0.46 & $1.04^{* *}$ & 0.47 & $1.06^{* *}$ & 0.46 \\
\hline English & 0.65 & 0.48 & 0.46 & 0.41 & 0.48 & 0.41 & 0.49 & 0.41 \\
\hline Latin, western & $1.23^{* *}$ & 0.51 & $0.99 * *$ & 0.45 & $1.01^{* *}$ & 0.45 & $0.99^{* *}$ & 0.45 \\
\hline Latin, nonwestern & $1.24^{* *}$ & 0.44 & $1.18^{* *}$ & 0.36 & $1.19^{* *}$ & 0.37 & $1.18^{* *}$ & 0.37 \\
\hline English 2nd lang. & 0.47 & 0.46 & 0.32 & 0.35 & 0.30 & 0.37 & 0.29 & 0.38 \\
\hline Africa & $1.02^{*}$ & 0.54 & $1.04^{*}$ & 0.57 & $1.10^{*}$ & 0.58 & $1.12^{*}$ & 0.57 \\
\hline Eastern Europe & 0.72 & 0.49 & 0.67 & 0.42 & $0.70^{*}$ & 0.43 & 0.69 & 0.43 \\
\hline Middle East & 0.53 & 0.50 & 0.67 & 0.42 & 0.70 & 0.43 & 0.69 & 0.44 \\
\hline Linguistic Distance & $-1.39^{* *}$ & 0.15 & $-0.80 * *$ & 0.17 & -0.41 & 0.30 & & \\
\hline \multicolumn{9}{|l|}{ Linguistic Dist. (foreign) } \\
\hline Ling. Dist. x Age at Migr. & & & & & -0.21 & 0.13 & $-0.35 * *$ & 0.08 \\
\hline Geographic distance & -0.04 & 0.03 & -0.04 & 0.03 & -0.03 & 0.03 & -0.03 & 0.03 \\
\hline Genetic distance & -0.84 & 2.08 & -2.29 & 2.09 & -2.40 & 2.08 & -2.47 & 2.04 \\
\hline Prim. Education & $-0.59^{* *}$ & 0.20 & $-0.62^{* *}$ & 0.22 & $-0.63^{* *}$ & 0.22 & $-0.64^{* *}$ & 0.23 \\
\hline Lower voc./prof. & -0.21 & 0.17 & $-0.44^{* *}$ & 0.18 & $-0.44^{* *}$ & 0.18 & $-0.44^{* *}$ & 0.18 \\
\hline Higher sec./middle voc. & -0.09 & 0.14 & -0.21 & 0.15 & -0.22 & 0.15 & -0.23 & 0.15 \\
\hline Age at migration & & & $-0.93^{* *}$ & 0.19 & $-0.89^{* *}$ & 0.19 & $-0.92^{* *}$ & 0.19 \\
\hline $\begin{array}{l}\text { Sqr. Of age at migr. } \\
\text { Age }\end{array}$ & & & $0.08^{* *}$ & 0.04 & $0.09^{* *}$ & 0.04 & $0.11^{* *}$ & 0.04 \\
\hline \multicolumn{9}{|l|}{ Female } \\
\hline \multicolumn{9}{|l|}{ \# Children } \\
\hline \multicolumn{9}{|l|}{ couple without children } \\
\hline \multicolumn{9}{|l|}{ Couple with children } \\
\hline \multicolumn{9}{|l|}{ Lone parent } \\
\hline \multicolumn{9}{|l|}{ Other household } \\
\hline \multicolumn{9}{|l|}{ Speak Dutch at home } \\
\hline \multicolumn{9}{|l|}{ Extremely urban } \\
\hline \multicolumn{9}{|l|}{ Very urban } \\
\hline \multicolumn{9}{|l|}{ moderately urban } \\
\hline Intercept & 0.41 & 0.49 & 1.75 & 0.46 & $1.65^{* *}$ & 0.47 & $1.57^{* *}$ & 0.45 \\
\hline Likelihood Value & -690.5 & & -591.3 & & -589.0 & & -590.7 & \\
\hline Pseudo R2 & 0.22 & & 0.34 & & 0.34 & & 0.34 & \\
\hline $\begin{array}{l}\text { Reference categories dummy } \\
\text { Not urban; Both Dutch ar } \\
* * / * \text { : significant at } 5 / 10 \%\end{array}$ & $\begin{array}{l}\text { ables: } A \\
\text { er nati } \\
\text { standa }\end{array}$ & ; & profes & ional & cationa & 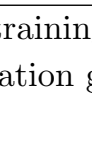 & $\begin{array}{l}\text { universi } \\
\text { oup. }\end{array}$ & igle; \\
\hline
\end{tabular}


Table 2: Probit regressions speaking fluency for sample of migrants (continued) $22<$ age $<65, N T=1303$

\begin{tabular}{|c|c|c|c|c|c|c|c|c|}
\hline Variable & Coef. & Std. & Coef. & Std. & Coef. & Std. & Coef. & Std. \\
\hline Turkey & 0.37 & 0.36 & 0.42 & 0.36 & 0.58 & 0.36 & $0.61^{*}$ & 0.37 \\
\hline Moroccan & 0.27 & 0.41 & 0.32 & 0.40 & 0.33 & 0.41 & 0.36 & 0.42 \\
\hline Dutch Antilles & $1.32^{* *}$ & 0.33 & $1.41^{* *}$ & 0.33 & $1.51^{* *}$ & 0.34 & $1.54^{* *}$ & 0.35 \\
\hline Suriname & $1.29^{* *}$ & 0.39 & $1.39^{* *}$ & 0.38 & $1.29^{* *}$ & 0.39 & $1.30^{* *}$ & 0.40 \\
\hline Indonesia & 0.58 & 0.38 & 0.60 & 0.38 & 0.59 & 0.38 & 0.58 & 0.38 \\
\hline German/Scand. & $1.03^{* *}$ & 0.46 & $1.07^{* *}$ & 0.46 & $1.01^{* *}$ & 0.46 & $0.99 * *$ & 0.47 \\
\hline English & 0.41 & 0.42 & 0.42 & 0.41 & 0.39 & 0.41 & 0.40 & 0.42 \\
\hline Latin, western & $0.98^{* *}$ & 0.46 & $1.03^{* *}$ & 0.46 & $0.89^{*}$ & 0.46 & $0.91^{*}$ & 0.46 \\
\hline Latin, nonwestern & $1.11^{* *}$ & 0.34 & $1.14^{* *}$ & 0.35 & $1.01^{* *}$ & 0.34 & $1.01^{* *}$ & 0.35 \\
\hline English 2nd lang. & 0.31 & 0.36 & 0.27 & 0.36 & 0.32 & 0.38 & 0.31 & 0.40 \\
\hline Africa & $1.16^{*}$ & 0.61 & $1.18^{*}$ & 0.58 & $1.11^{*}$ & 0.58 & $1.16^{* *}$ & 0.56 \\
\hline Eastern Europe & $0.76^{*}$ & 0.43 & $0.76^{*}$ & 0.43 & $0.70^{*}$ & 0.43 & $0.77^{*}$ & 0.43 \\
\hline Middle East & 0.66 & 0.45 & 0.69 & 0.44 & 0.68 & 0.46 & 0.66 & 0.47 \\
\hline Linguistic Distance & -0.23 & 0.30 & -0.18 & 0.30 & -0.10 & 0.30 & -0.16 & 0.31 \\
\hline \multicolumn{9}{|l|}{ Linguistic Dist. (foreign) } \\
\hline Ling. Dist. x Age at Migr. & $-0.27^{* *}$ & 0.13 & $-0.29^{* *}$ & 0.13 & $-0.27^{* *}$ & 0.14 & $-0.27^{* *}$ & 0.14 \\
\hline Geographic distance & -0.02 & 0.03 & -0.02 & 0.03 & -0.02 & 0.03 & -0.02 & 0.03 \\
\hline Genetic distance & -2.71 & 2.23 & -2.67 & 2.19 & -2.91 & 2.21 & -2.98 & 2.19 \\
\hline Prim. Education & $-0.66^{* *}$ & 0.24 & $-0.62^{* *}$ & 0.23 & $-0.57 * *$ & 0.24 & $-0.55^{* *}$ & 0.24 \\
\hline Lower voc./prof. & $-0.51^{* *}$ & 0.18 & $-0.55^{* *}$ & 0.18 & $-0.54^{* *}$ & 0.18 & $-0.55^{* *}$ & 0.18 \\
\hline Higher sec./middle voc. & -0.21 & 0.15 & -0.20 & 0.15 & -0.18 & 0.15 & -0.18 & 0.16 \\
\hline Age at migration & $-0.88^{* *}$ & 0.19 & $-0.93^{* *}$ & 0.18 & $-0.89^{* *}$ & 0.18 & $-0.92^{* *}$ & 0.19 \\
\hline Sqr. Of age at migr. & $0.08^{* *}$ & 0.04 & $0.09^{* *}$ & 0.04 & $0.09^{* *}$ & 0.04 & $0.10^{* *}$ & 0.04 \\
\hline Age & $0.22^{* *}$ & 0.07 & $0.23^{* *}$ & 0.07 & $0.18^{* *}$ & 0.07 & $0.20^{* *}$ & 0.07 \\
\hline Female & -0.01 & 0.13 & 0.06 & 0.13 & 0.02 & 0.13 & 0.01 & 0.13 \\
\hline \# Children & & & 0.05 & 0.09 & 0.07 & 0.09 & 0.08 & 0.10 \\
\hline couple without children & & & -0.16 & 0.20 & -0.18 & 0.20 & -0.14 & 0.20 \\
\hline Couple with children & & & -0.19 & 0.24 & -0.24 & 0.24 & -0.21 & 0.25 \\
\hline Lone parent & & & $-0.55^{*}$ & 0.30 & $-0.59^{*}$ & 0.30 & $-0.55^{*}$ & 0.30 \\
\hline Other household & & & -0.75 & 0.59 & -0.73 & 0.60 & -0.63 & 0.58 \\
\hline Speak Dutch at home & & & & & 0.54 & 0.13 & 0.53 & 0.13 \\
\hline Extremely urban & & & & & & & -0.17 & 0.35 \\
\hline Very urban & & & & & & & -0.33 & 0.33 \\
\hline moderately urban & & & & & & & -0.55 & 0.34 \\
\hline slightly urban & & & & & & & -0.14 & 0.37 \\
\hline Intercept & 0.78 & 0.52 & 0.84 & 0.55 & 0.53 & 0.56 & 0.78 & 0.66 \\
\hline Likelihood Value & -578.4 & & -572.9 & & -559.0 & & -552.1 & \\
\hline Pseudo R2 & 0.35 & & 0.36 & & 0.37 & & 0.38 & \\
\hline
\end{tabular}


Table 3: Descriptive statistics instrumental variables from Personality and Politics and Values section $22<$ age $<65, N T=1111$

\begin{tabular}{|c|c|c|c|c|c|}
\hline Personality section & $\begin{array}{c}\text { very } \\
\text { inaccurate }\end{array}$ & $\begin{array}{l}\text { moderately } \\
\text { inaccurate }\end{array}$ & $\begin{array}{c}\text { in } \\
\text { between }\end{array}$ & $\begin{array}{c}\text { moderately } \\
\text { accurate }\end{array}$ & $\begin{array}{c}\text { very } \\
\text { accurate }\end{array}$ \\
\hline I have a rich vocabulary & 1.9 & 11.7 & 32.6 & 40.9 & 13.0 \\
\hline I am quick to understand things & 0.2 & 3.8 & 22.7 & 53.5 & 19.9 \\
\hline \multirow{2}{*}{\multicolumn{6}{|c|}{$\begin{array}{l}\text { Politics and Values section } \\
\text { It is difficult for a foreigner to be accepted in the Netherlands while retaining his/her own culture } \\
\text { fully } \\
\begin{array}{llclll}\text { disagree } & \text { disagree } & \text { in } & \text { agree } & \text { fully } & \text { missing } \\
& & \text { between } & & \text { agree }\end{array}\end{array}$}} \\
\hline & & & & & \\
\hline 3.0 & 14.7 & 27.4 & 35.3 & 11.8 & 7.9 \\
\hline
\end{tabular}


Table 4: Probit regressions speaking fluency for sample of migrants including instrumental variables from "personality" and "politics and values" section $22<$ age $<65, N T=1111$

\begin{tabular}{|c|c|c|c|c|}
\hline Variable & Coef. & Std. & Coef. & Std. \\
\hline Turkey & 0.44 & 0.40 & 0.43 & 0.40 \\
\hline Moroccan & 0.18 & 0.45 & 0.13 & 0.44 \\
\hline Dutch Antilles & $1.35^{* *}$ & 0.38 & $1.40^{* *}$ & 0.38 \\
\hline Suriname & $1.54^{* *}$ & 0.42 & $1.67^{* *}$ & 0.41 \\
\hline Indonesia & 0.58 & 0.43 & 0.66 & 0.41 \\
\hline German/Scand. & $1.26^{* *}$ & 0.50 & $1.37^{* *}$ & 0.50 \\
\hline English & 0.65 & 0.44 & 0.73 & 0.44 \\
\hline Latin, western & $1.24^{* *}$ & 0.53 & $1.24^{* *}$ & 0.51 \\
\hline Latin, nonwestern & $1.35^{* *}$ & 0.41 & $1.34^{* *}$ & 0.39 \\
\hline English 2nd lang. & 0.33 & 0.40 & 0.27 & 0.40 \\
\hline Africa & 1.20 & 0.66 & $1.07^{*}$ & 0.66 \\
\hline Eastern Europe & $0.93^{*}$ & 0.49 & $0.90^{*}$ & 0.48 \\
\hline Middle East & 0.91 & 0.53 & $0.81^{*}$ & 0.52 \\
\hline Ling. Dist. $\mathrm{x}$ Age at Migr. & $-0.34^{* *}$ & 0.09 & $-0.34^{* *}$ & 0.09 \\
\hline Geographic distance & -0.03 & 0.03 & -0.03 & 0.03 \\
\hline Genetic distance & -1.21 & 2.19 & -0.83 & 2.14 \\
\hline Prim. Education & -0.32 & 0.28 & -0.47 & 0.29 \\
\hline Lower voc./prof. & -0.32 & 0.21 & -0.43 & 0.20 \\
\hline Higher sec./middle voc. & 0.10 & 0.18 & 0.02 & 0.18 \\
\hline Age at migration & $-0.83^{* *}$ & 0.20 & $-0.89 * *$ & 0.20 \\
\hline Sqr. Of age at migr. & 0.06 & 0.04 & 0.07 & 0.04 \\
\hline Age & $0.27^{* *}$ & 0.07 & $0.26^{* *}$ & 0.07 \\
\hline Female & -0.05 & 0.14 & -0.08 & 0.14 \\
\hline \# Children & -0.52 & 1.15 & -0.49 & 1.15 \\
\hline couple without children & -0.23 & 0.22 & -0.24 & 0.22 \\
\hline Couple with children & -0.05 & 0.29 & -0.10 & 0.29 \\
\hline Lone parent & -0.47 & 0.35 & -0.47 & 0.35 \\
\hline Other household & $-1.20 * *$ & 0.67 & $-1.27^{*}$ & 0.65 \\
\hline Rich vocabulary:in between & 0.26 & 0.17 & & \\
\hline Rich vocabulary: accurate & $0.70^{* *}$ & 0.18 & & \\
\hline Rich vocabulary:very accurate & $0.84^{* *}$ & 0.22 & & \\
\hline Quickly understand:accurate & $0.41^{* *}$ & 0.13 & $0.56^{* *}$ & 0.13 \\
\hline Quickly understand:very accurate & $0.58^{* *}$ & 0.19 & $0.82^{* *}$ & 0.18 \\
\hline foreigner diff. accepted:disagree & & & $0.40^{* *}$ & 0.14 \\
\hline Intercept & -0.44 & 0.68 & -0.03 & 0.67 \\
\hline Likelihood Value & -443.9 & & -453.9 & \\
\hline Pseudo R2 & 0.42 & & 0.40 & \\
\hline \multicolumn{5}{|c|}{$\begin{array}{l}\text { Reference categories dummy variables: Asia; Higher professional/vocational training, university; Single; } \\
\text { Not urban; Both Dutch and other nationality; Both Dutch and other population group. } \\
* * / * \text { : significant at } 5 / 10 \% \text { level; standard errors adjusted for clustering. }\end{array}$} \\
\hline
\end{tabular}




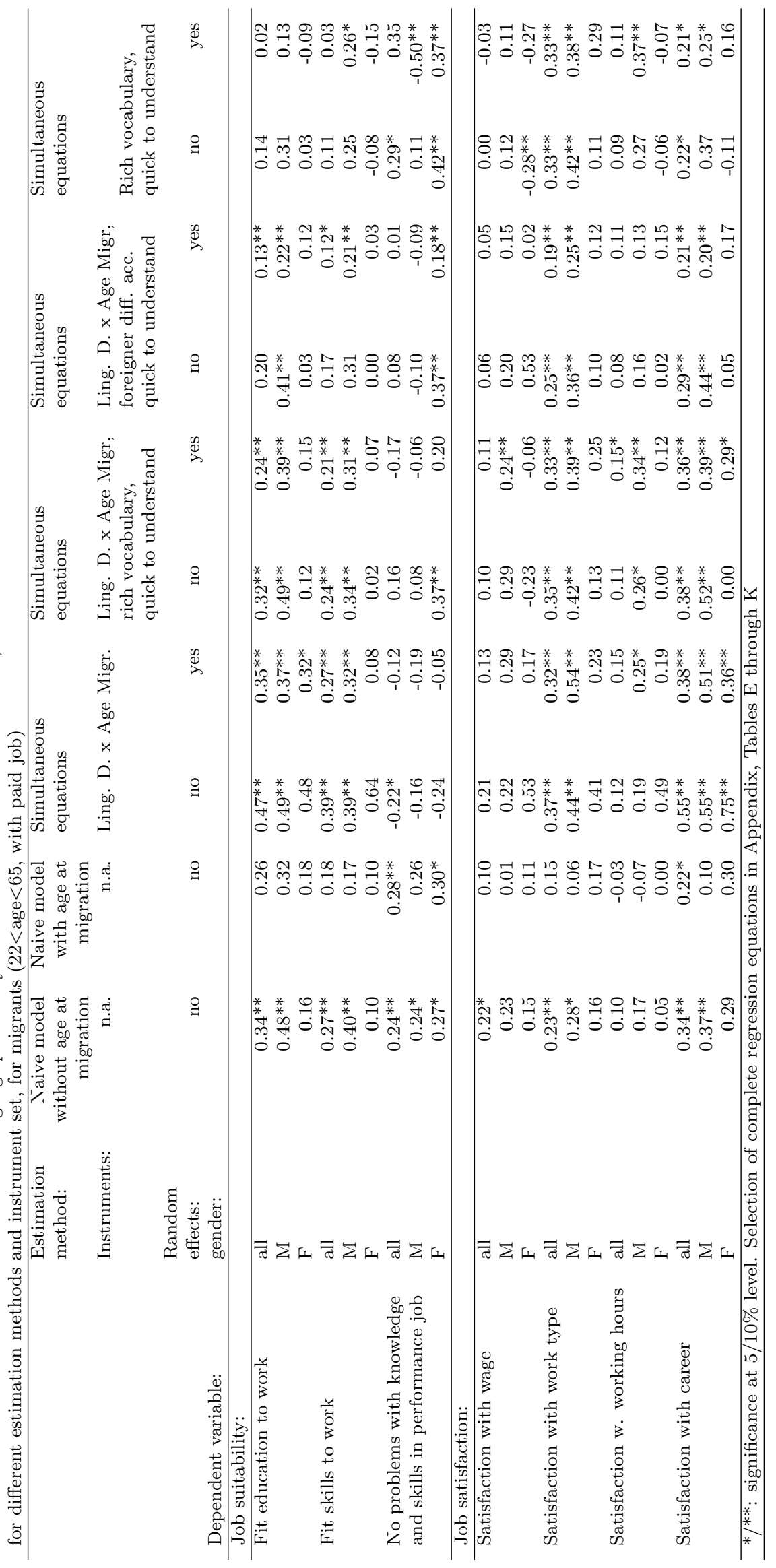




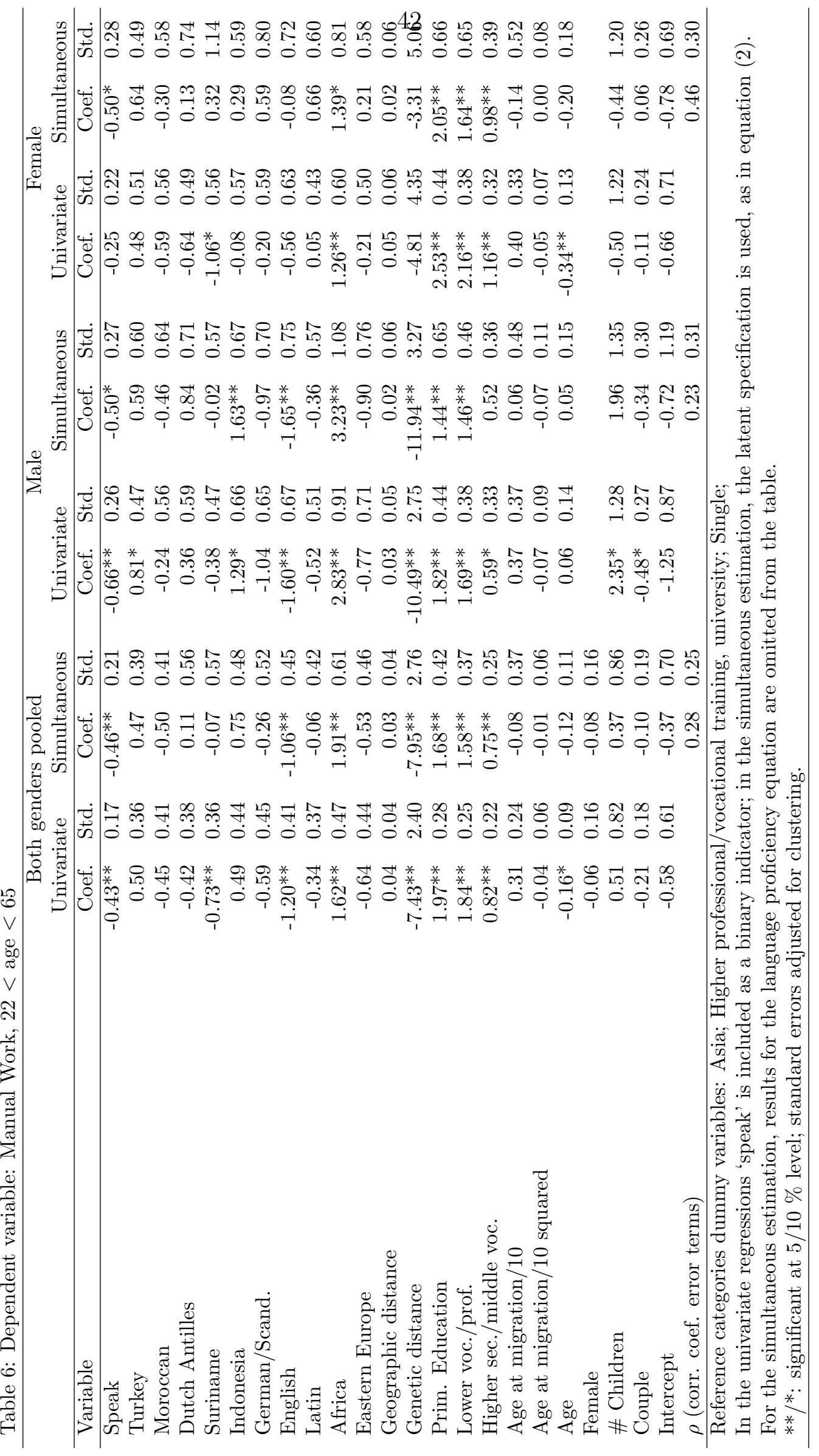




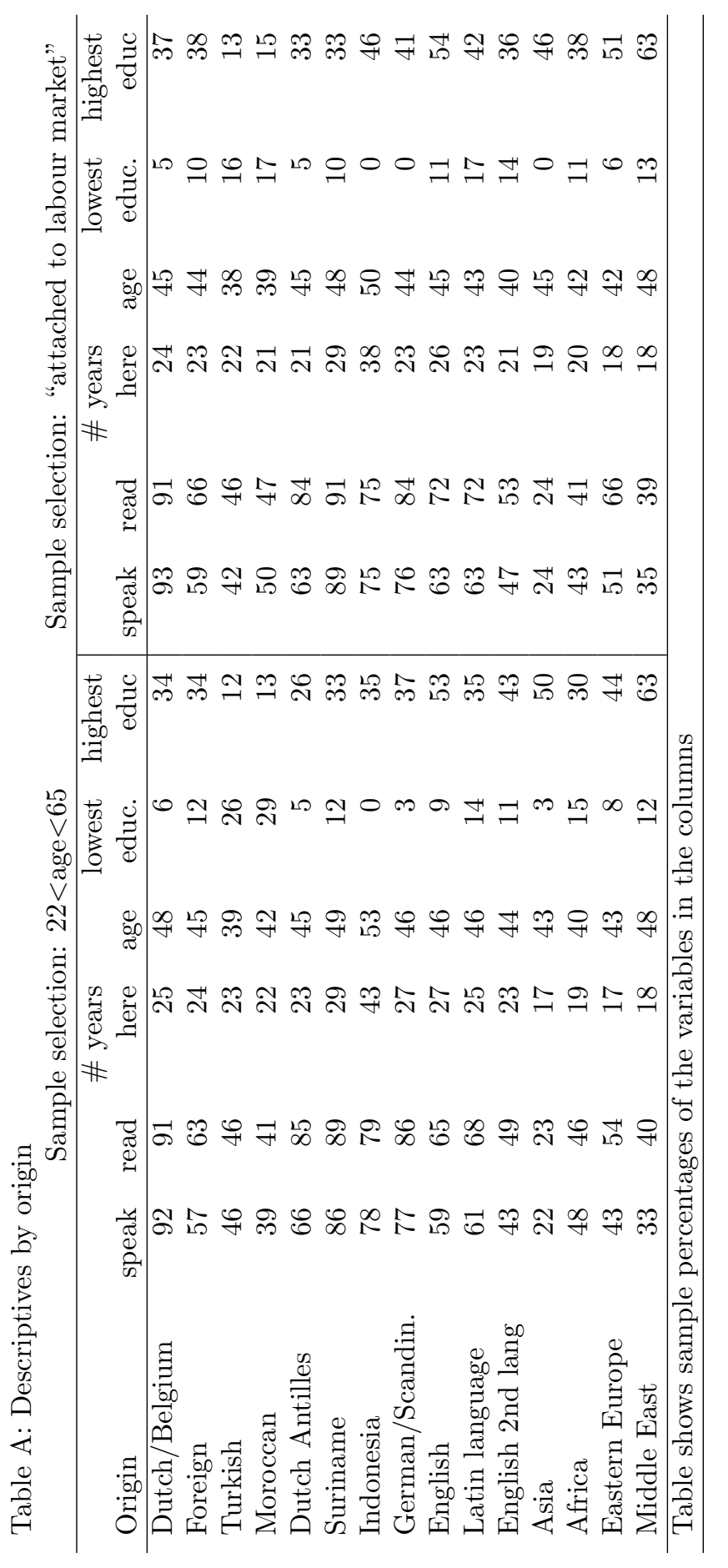


Table B: Probit regressions Dutch spoken at home by migrants $22<$ age $<65, N T=1303$

\begin{tabular}{lrrrr}
\hline Variable & Coef. & Std. & Coef. & Std. \\
\hline Turkey & $-1.02^{* *}$ & 0.41 & $-1.03^{* *}$ & 0.41 \\
Moroccan & -0.22 & 0.41 & -0.21 & 0.41 \\
Dutch Antilles & -0.43 & 0.38 & -0.46 & 0.38 \\
Suriname & $0.88^{* *}$ & 0.39 & $0.93^{* *}$ & 0.39 \\
Indonesia & 0.22 & 0.59 & 0.23 & 0.60 \\
German/Scand. & 0.24 & 0.46 & 0.24 & 0.46 \\
English & -0.15 & 0.41 & -0.12 & 0.41 \\
Latin, western & 0.54 & 0.50 & 0.51 & 0.50 \\
Latin, nonwestern & $0.78^{* *}$ & 0.39 & $0.79^{* *}$ & 0.39 \\
English 2nd lang. & $-0.61^{*}$ & 0.36 & $-0.61^{*}$ & 0.36 \\
Africa & 0.32 & 0.40 & 0.30 & 0.39 \\
Eastern Europe & 0.13 & 0.43 & 0.11 & 0.43 \\
Middle East & -0.05 & 0.44 & -0.04 & 0.44 \\
Linguistic Distance & $-0.73^{* *}$ & 0.18 & $-0.73^{* *}$ & 0.18 \\
Geographic Distance & -0.03 & 0.03 & -0.03 & 0.03 \\
Genetic distance & 0.90 & 1.50 & 1.15 & 1.52 \\
Prim. Education & $-0.35^{*}$ & 0.19 & $-0.34^{*}$ & 0.19 \\
Lower voc./prof. & -0.15 & 0.18 & -0.13 & 0.18 \\
Higher sec./middle voc. & -0.10 & 0.15 & -0.09 & 0.15 \\
Age at migration & $-0.71^{* *}$ & 0.19 & $-0.72^{* *}$ & 0.19 \\
Sqr. Of age at migr. & 0.06 & 0.04 & 0.06 & 0.04 \\
Age & $1.33^{* *}$ & 0.48 & $1.32^{* *}$ & 0.48 \\
Age squared & $-0.12^{* *}$ & 0.06 & $-0.12^{* *}$ & 0.06 \\
Female & $0.34^{* *}$ & 0.13 & 0.53 & 0.32 \\
\# Children & $-0.20^{* *}$ & 0.10 & -0.29 & 0.17 \\
couple without children & 0.14 & 0.20 & 0.12 & 0.28 \\
Couple with children & 0.35 & 0.26 & $0.67^{*}$ & 0.40 \\
Lone parent & 0.06 & 0.31 & -0.07 & 0.61 \\
Other household & -0.43 & 0.43 & 0.02 & 0.56 \\
Female $\times$ \# Children & & & -0.55 & 0.53 \\
Female $\times$ couple without children & & & -0.03 & 0.42 \\
Female $\times$ Couple with children & & & -0.78 & 0.81 \\
Female $\times$ Lone parent & & & 0.02 & 0.71 \\
Female $\times$ Other household & & & 0.11 & 0.20 \\
Intercept & -1.15 & 1.12 & -1.20 & 1.13 \\
\hline Likelihood Value & -565.2 & & -562.7 & \\
Pseudo R2 & 0.30 & & 0.30 & \\
\hline Rer & & & &
\end{tabular}

Reference categories dummy variables:

Asia; Higher professional/vocational training, university; Single.

**/*: significant at $5 / 10 \%$ level; standard errors adjusted for clustering. 
Table C: Probit regressions for literacy, $22<$ age $<65, N T=1303$

and fluency, subsample of migrants attached to the labour force, $N T=723$

\begin{tabular}{|c|c|c|c|c|}
\hline \multirow[b]{2}{*}{ Variable } & \multicolumn{2}{|c|}{ literacy } & \multicolumn{2}{|c|}{$\begin{array}{c}\text { subsample } \\
\text { fluency }\end{array}$} \\
\hline & Coef. & Std. & Coef. & Std. \\
\hline Turkey & 0.44 & 0.33 & 0.14 & 0.41 \\
\hline Moroccan & 0.41 & 0.37 & 0.18 & 0.46 \\
\hline Dutch Antilles & $1.95^{* *}$ & 0.29 & $1.47^{* *}$ & 0.39 \\
\hline Suriname & $1.99 * *$ & 0.35 & $1.54^{* *}$ & 0.45 \\
\hline Indonesia & $0.77^{* *}$ & 0.35 & 0.74 & 0.44 \\
\hline German/Scand. & $1.52^{* *}$ & 0.44 & 0.65 & 0.52 \\
\hline English & $0.73^{*}$ & 0.37 & 0.42 & 0.47 \\
\hline Latin, western & $1.20 * *$ & 0.44 & $0.89^{*}$ & 0.49 \\
\hline Latin, nonwestern & $1.32^{* *}$ & 0.30 & $1.27^{* *}$ & 0.38 \\
\hline English 2nd lang. & $0.56^{*}$ & 0.29 & 0.22 & 0.41 \\
\hline Africa & 0.70 & 0.50 & 0.90 & 0.58 \\
\hline Eastern Europe & $0.85^{* *}$ & 0.39 & 0.38 & 0.48 \\
\hline Middle East & 0.61 & 0.39 & 0.51 & 0.49 \\
\hline Linguistic distance & $-0.35 * *$ & 0.16 & $-0.74^{* *}$ & 0.21 \\
\hline Geographic distance & -0.04 & 0.03 & $-0.06^{*}$ & 0.03 \\
\hline Genetic distance & -0.50 & 1.91 & -3.23 & 2.42 \\
\hline Prim. Education & $-1.02 * *$ & 0.21 & $-0.68^{* *}$ & 0.27 \\
\hline Lower voc./prof. & $-0.68 * *$ & 0.18 & $-0.64^{* *}$ & 0.20 \\
\hline Higher sec./middle voc. & -0.04 & 0.15 & -0.18 & 0.17 \\
\hline Age at migration & $-0.81^{* *}$ & 0.18 & $-1.08 * *$ & 0.23 \\
\hline Sqr. Of age at migr. & $0.07^{*}$ & 0.04 & $0.10^{* *}$ & 0.05 \\
\hline Age & $0.22^{* *}$ & 0.07 & $0.21^{* *}$ & 0.08 \\
\hline Female & -0.06 & 0.13 & $0.32^{* *}$ & 0.14 \\
\hline \# Children & 0.03 & 0.09 & -0.08 & 0.12 \\
\hline couple without children & $-0.42^{* *}$ & 0.19 & -0.10 & 0.23 \\
\hline Couple with children & -0.26 & 0.23 & 0.02 & 0.28 \\
\hline Lone parent & -0.25 & 0.29 & $-0.68^{* *}$ & 0.34 \\
\hline Other household & $-1.05^{*}$ & 0.54 & -0.76 & 0.77 \\
\hline Intercept & 0.63 & 0.51 & $1.41^{* *}$ & 0.62 \\
\hline Likelihood Value & -585.1 & & -410.9 & \\
\hline Pseudo R2 & 0.32 & & 0.35 & \\
\hline
\end{tabular}

Reference categories dummy variables:

Asia; Higher professional/vocational training, university; Single.

**/*: significant at 5/10 \% level; standard errors adjusted for clustering. 
Table D: Response to job satisfaction and job suitability questions of migrants, $22<$ age $<65$, with paid job

\begin{tabular}{|c|c|c|c|c|c|c|c|}
\hline \multicolumn{8}{|c|}{ Both men and women: } \\
\hline $\begin{array}{r}\text { Response } \\
\text { category }\end{array}$ & $\begin{array}{r}\text { Fit education } \\
\text { and work }\end{array}$ & $\begin{array}{r}\text { Fit skills } \\
\text { work }\end{array}$ & $\begin{array}{r}\text { Job } \\
\text { performance }\end{array}$ & $\begin{array}{r}\text { Satisfaction } \\
\text { Wage }\end{array}$ & $\begin{array}{l}\text { Satisfaction } \\
\text { type of work }\end{array}$ & $\begin{array}{r}\text { Satisfaction } \\
\text { hours }\end{array}$ & $\begin{array}{r}\text { Satisfaction } \\
\text { career }\end{array}$ \\
\hline 0 & 12.4 & 5.6 & 0.6 & 4.5 & 2.9 & 0.7 & 2.1 \\
\hline 1 & 3.6 & 1.9 & 1.4 & 1.2 & 0.6 & 0.4 & 1.1 \\
\hline 2 & 5.6 & 1.8 & 1.0 & 4.5 & 1.3 & 2.3 & 2.0 \\
\hline 3 & 2.8 & 3.0 & 1.8 & 6.1 & 2.6 & 1.7 & 2.3 \\
\hline 4 & 6.6 & 4.7 & 3.2 & 6.3 & 2.0 & 2.4 & 3.3 \\
\hline 5 & 7.4 & 6.6 & 4.6 & 13.3 & 8.0 & 8.1 & 9.0 \\
\hline 6 & 11.7 & 10.2 & 5.5 & 13.8 & 9.3 & 11.3 & 14.3 \\
\hline 7 & 15.7 & 18.1 & 12.4 & 20.8 & 19.5 & 21.3 & 23.9 \\
\hline 8 & 17.9 & 26.4 & 20.4 & 19.5 & 28.1 & 27.6 & 26.3 \\
\hline 9 & 8.2 & 13.9 & 21.6 & 7.2 & 16.1 & 13.7 & 10.4 \\
\hline 10 & 8.2 & 7.8 & 27.7 & 3.0 & 9.7 & 10.4 & 5.3 \\
\hline Nobs & 728 & 728 & 726 & 694 & 701 & 700 & 700 \\
\hline \multicolumn{8}{|l|}{ Men only: } \\
\hline $\begin{array}{r}\text { Response } \\
\text { category }\end{array}$ & $\begin{array}{r}\text { Fit education } \\
\text { and work }\end{array}$ & $\begin{array}{r}\text { Fit skills } \\
\text { work }\end{array}$ & $\begin{array}{r}\text { Job } \\
\text { performance }\end{array}$ & $\begin{array}{r}\text { Satisfaction } \\
\text { wage }\end{array}$ & $\begin{array}{l}\text { Satisfaction } \\
\text { type of work }\end{array}$ & $\begin{array}{r}\text { Satisfaction } \\
\text { hours }\end{array}$ & $\begin{array}{r}\text { Satisfaction } \\
\text { career }\end{array}$ \\
\hline 0 & 9.3 & 4.4 & 0.3 & 3.2 & 2.0 & 0.3 & 1.4 \\
\hline 1 & 4.4 & 1.1 & 1.6 & 0.9 & 0.3 & 0.0 & 0.9 \\
\hline 2 & 4.1 & 1.6 & 1.4 & 3.5 & 1.1 & 2.3 & 2.3 \\
\hline 3 & 3.3 & 3.6 & 2.5 & 5.8 & 2.3 & 0.9 & 1.7 \\
\hline 4 & 6.3 & 3.6 & 2.7 & 6.3 & 2.3 & 3.4 & 4.0 \\
\hline 5 & 7.7 & 7.1 & 3.8 & 15.0 & 8.8 & 9.7 & 10.2 \\
\hline 6 & 13.7 & 8.7 & 5.5 & 13.0 & 10.2 & 10.0 & 14.7 \\
\hline 7 & 18.3 & 18.9 & 12.6 & 18.4 & 21.0 & 20.2 & 22.4 \\
\hline 8 & 18.3 & 29.0 & 17.5 & 19.6 & 24.9 & 28.8 & 24.4 \\
\hline 9 & 7.7 & 15.0 & 22.5 & 10.1 & 17.6 & 13.1 & 11.9 \\
\hline 10 & 7.1 & 7.1 & 29.6 & 4.3 & 9.6 & 11.4 & 6.2 \\
\hline Nobs & 366 & 366 & 365 & 347 & 353 & 351 & 353 \\
\hline \multicolumn{8}{|c|}{ Women only: } \\
\hline $\begin{array}{r}\text { Response } \\
\text { category }\end{array}$ & $\begin{array}{r}\text { Fit education } \\
\text { and work }\end{array}$ & $\begin{array}{r}\text { Fit skills } \\
\text { work }\end{array}$ & $\begin{array}{r}\text { Job } \\
\text { performance }\end{array}$ & $\begin{array}{r}\text { Satisfaction } \\
\text { Wage }\end{array}$ & $\begin{array}{l}\text { Satisfaction } \\
\text { type of work }\end{array}$ & $\begin{array}{r}\text { Satisfaction } \\
\text { hours }\end{array}$ & $\begin{array}{r}\text { Satisfaction } \\
\text { career }\end{array}$ \\
\hline 0 & 15.5 & 6.9 & 0.8 & 5.8 & 3.7 & 1.2 & 2.9 \\
\hline 1 & 2.8 & 2.8 & 1.1 & 1.4 & 0.9 & 0.9 & 1.4 \\
\hline 2 & 7.2 & 1.9 & 0.6 & 5.5 & 1.4 & 2.3 & 1.7 \\
\hline 3 & 2.2 & 2.5 & 1.1 & 6.3 & 2.9 & 2.6 & 2.9 \\
\hline 4 & 6.9 & 5.8 & 3.6 & 6.3 & 1.7 & 1.4 & 2.6 \\
\hline 5 & 7.2 & 6.1 & 5.3 & 11.5 & 7.2 & 6.6 & 7.8 \\
\hline 6 & 9.7 & 11.6 & 5.5 & 14.7 & 8.3 & 12.6 & 13.8 \\
\hline 7 & 13.0 & 17.4 & 12.2 & 23.1 & 18.1 & 22.4 & 25.4 \\
\hline 8 & 17.4 & 23.8 & 23.3 & 19.3 & 31.3 & 26.4 & 28.2 \\
\hline 9 & 8.8 & 12.7 & 20.8 & 4.3 & 14.7 & 14.3 & 8.9 \\
\hline 10 & 9.4 & 8.6 & 25.8 & 1.7 & 9.8 & 9.5 & 4.3 \\
\hline Nobs & 362 & 362 & 361 & 347 & 348 & 349 & 347 \\
\hline
\end{tabular}




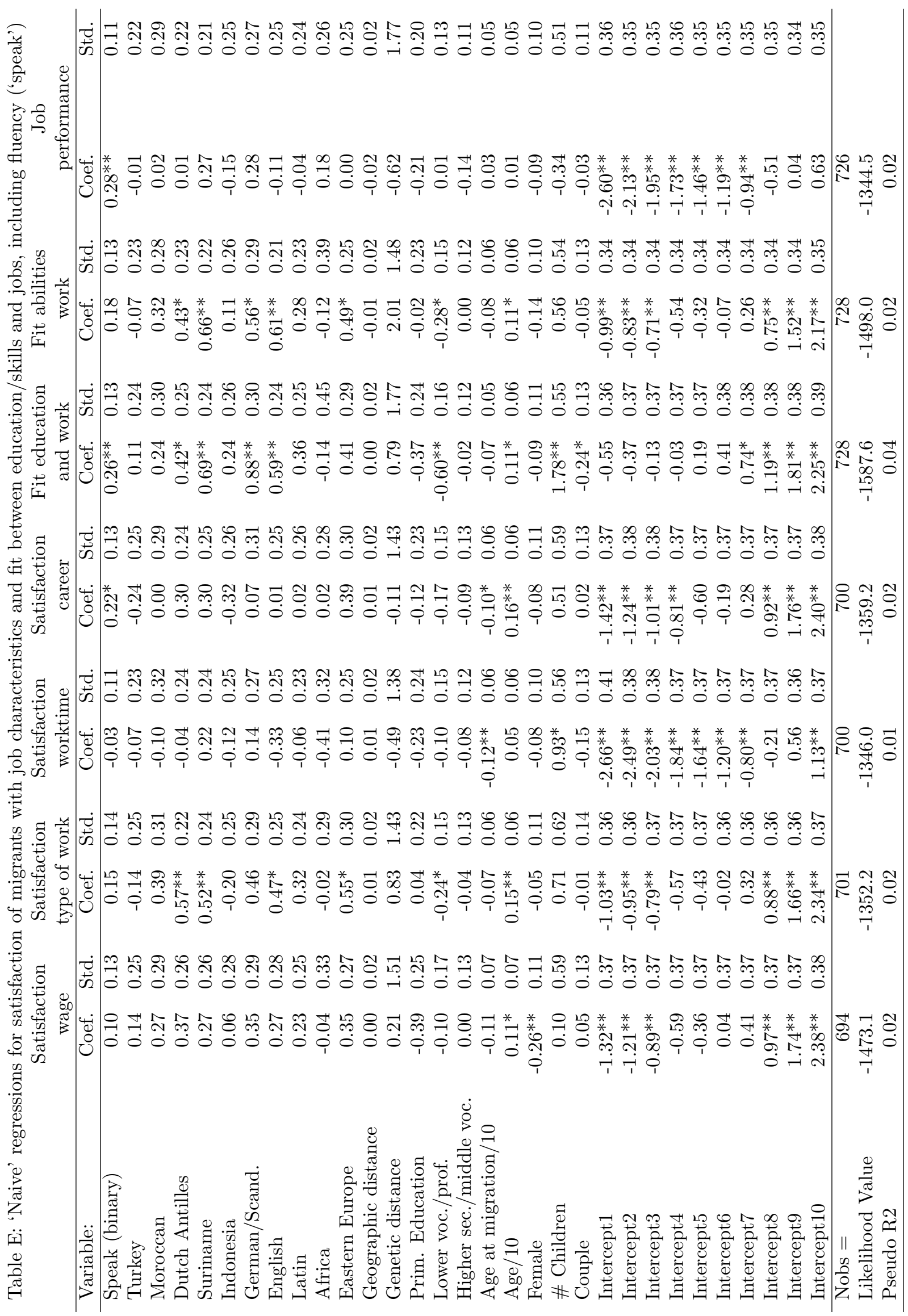




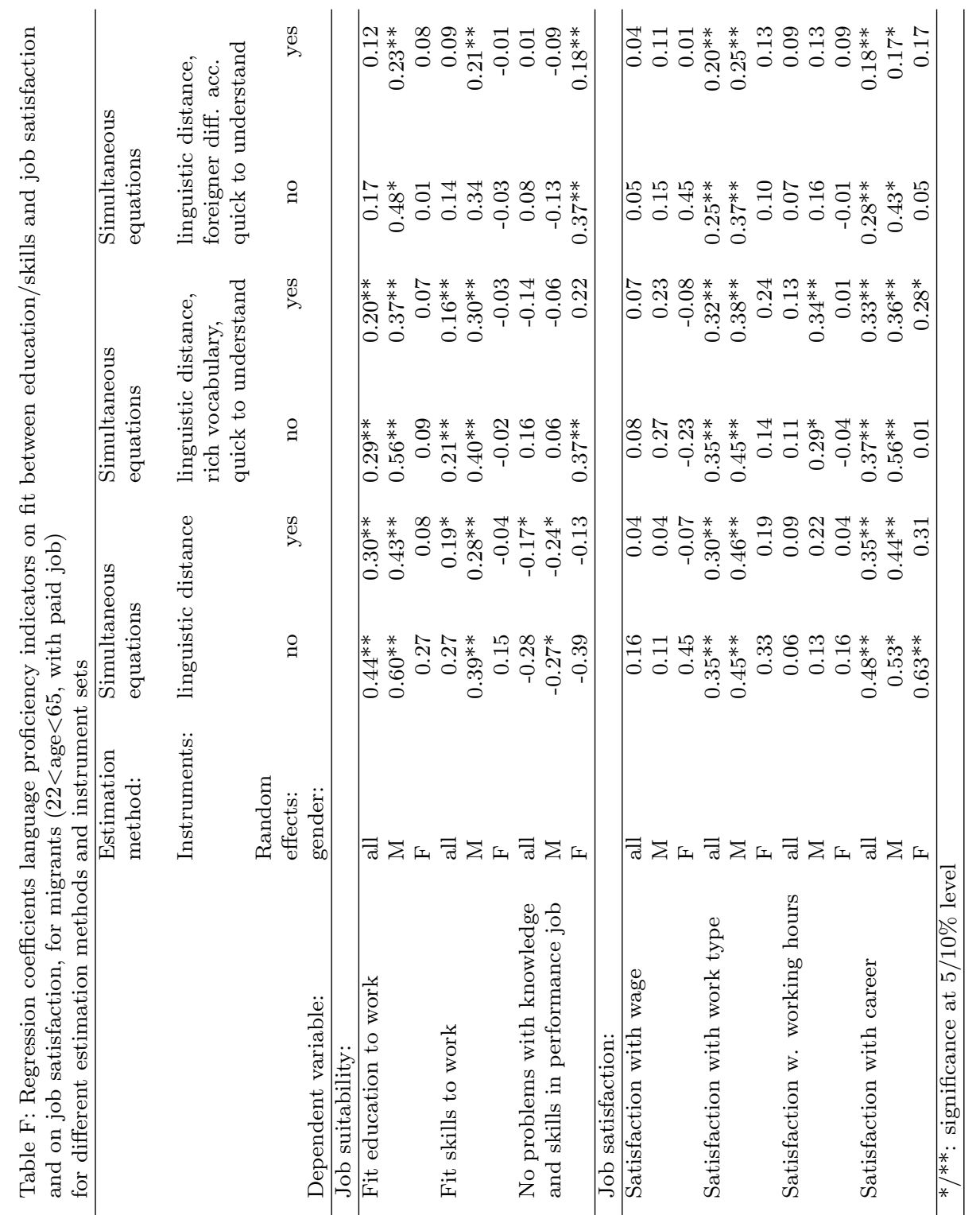




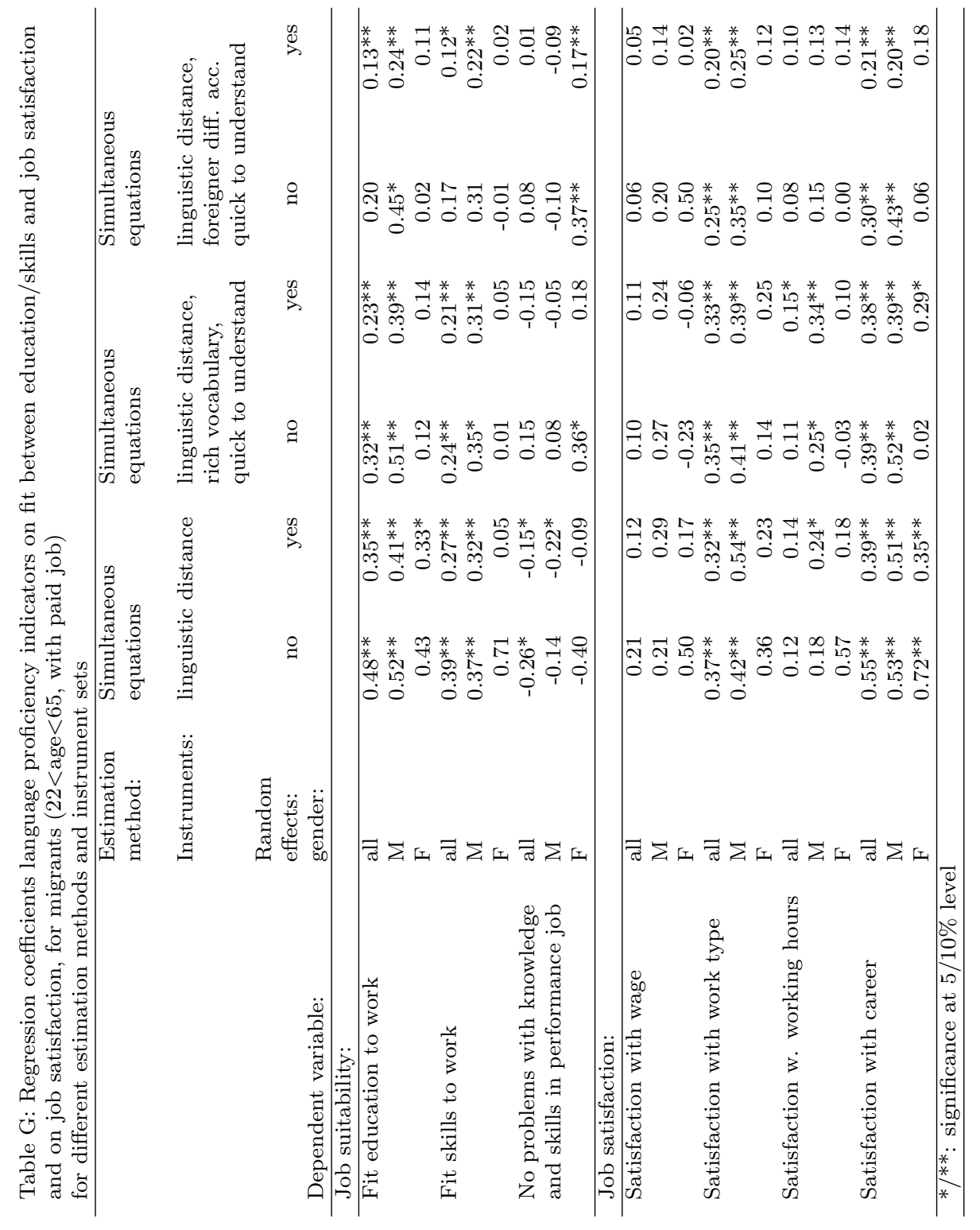




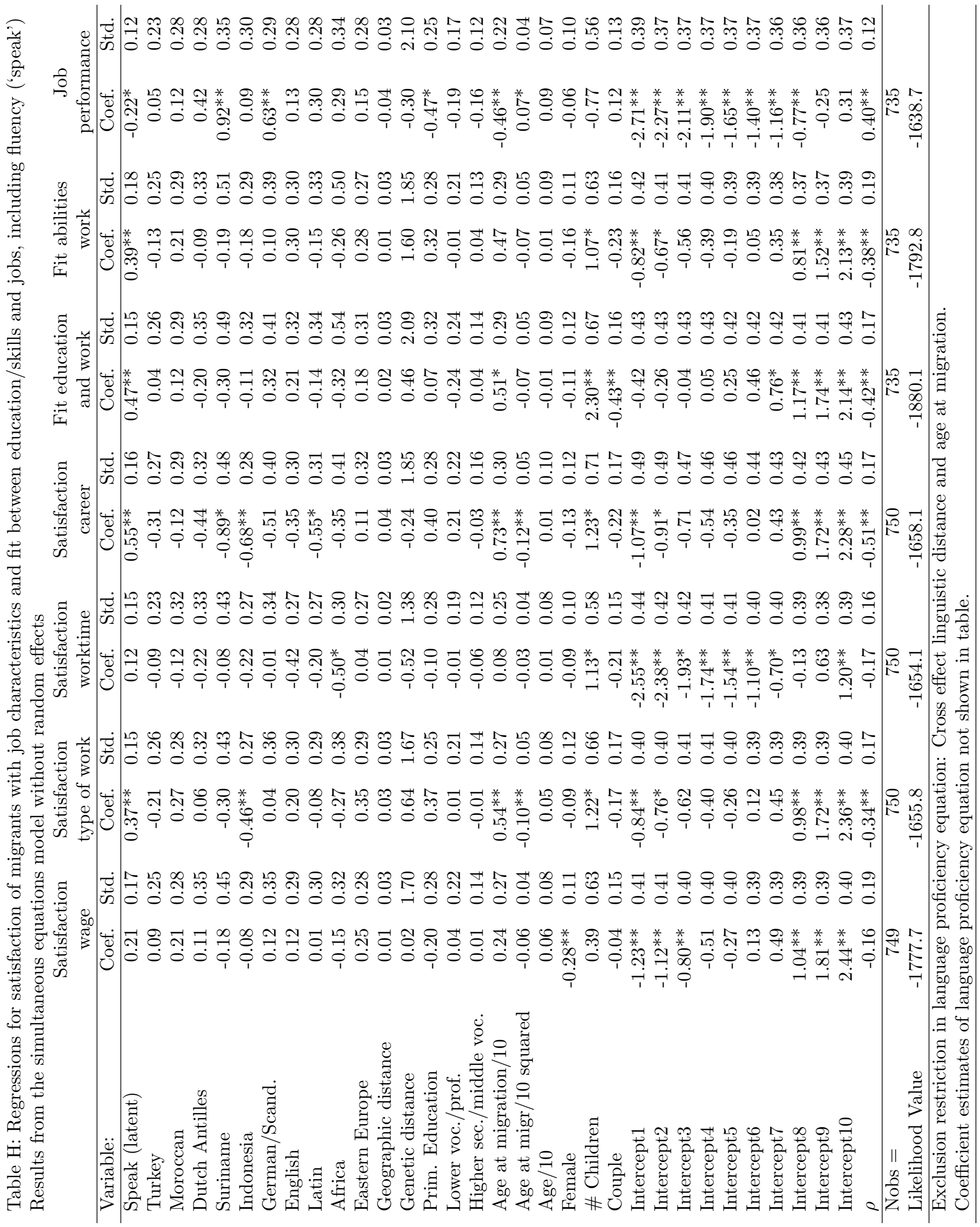




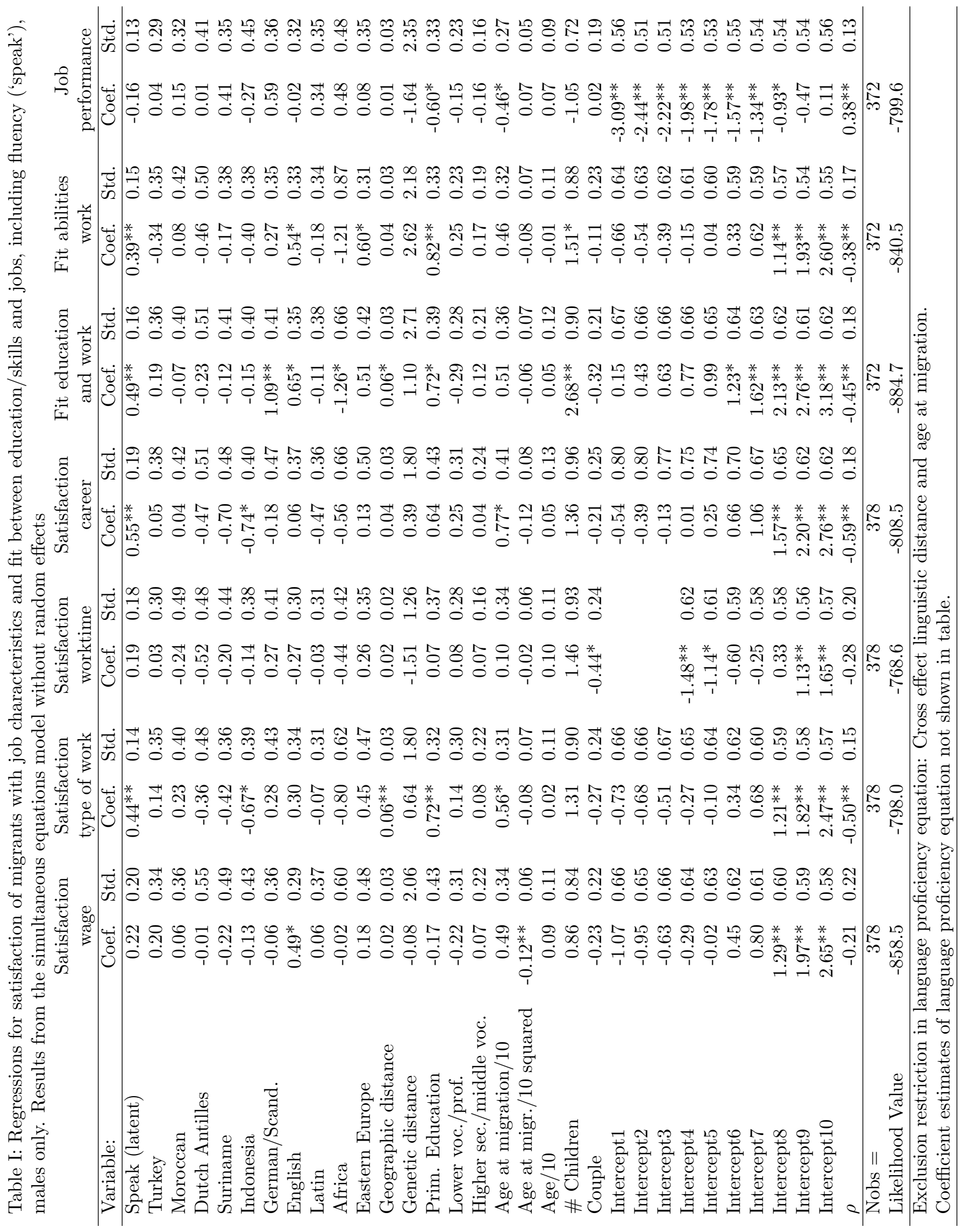




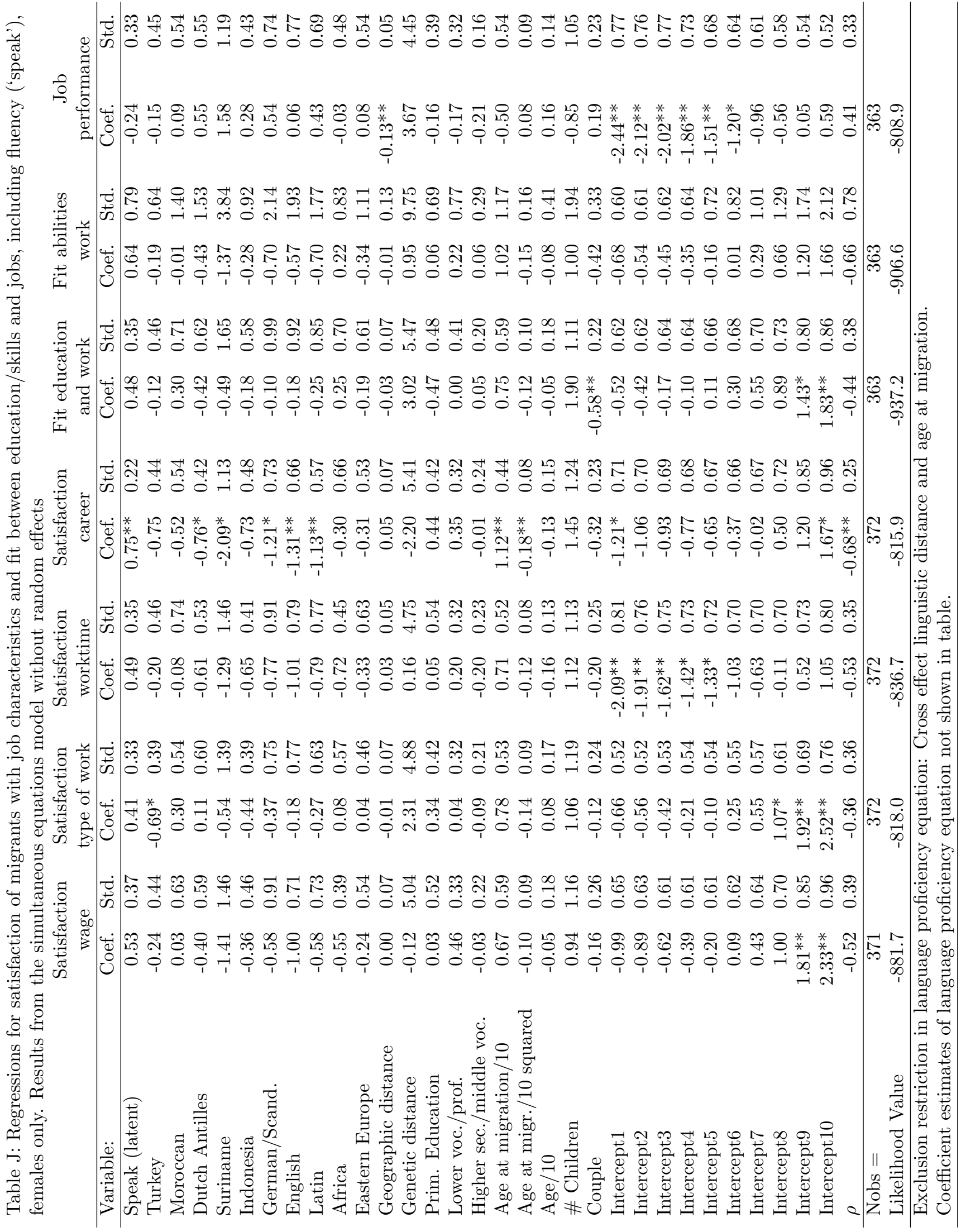




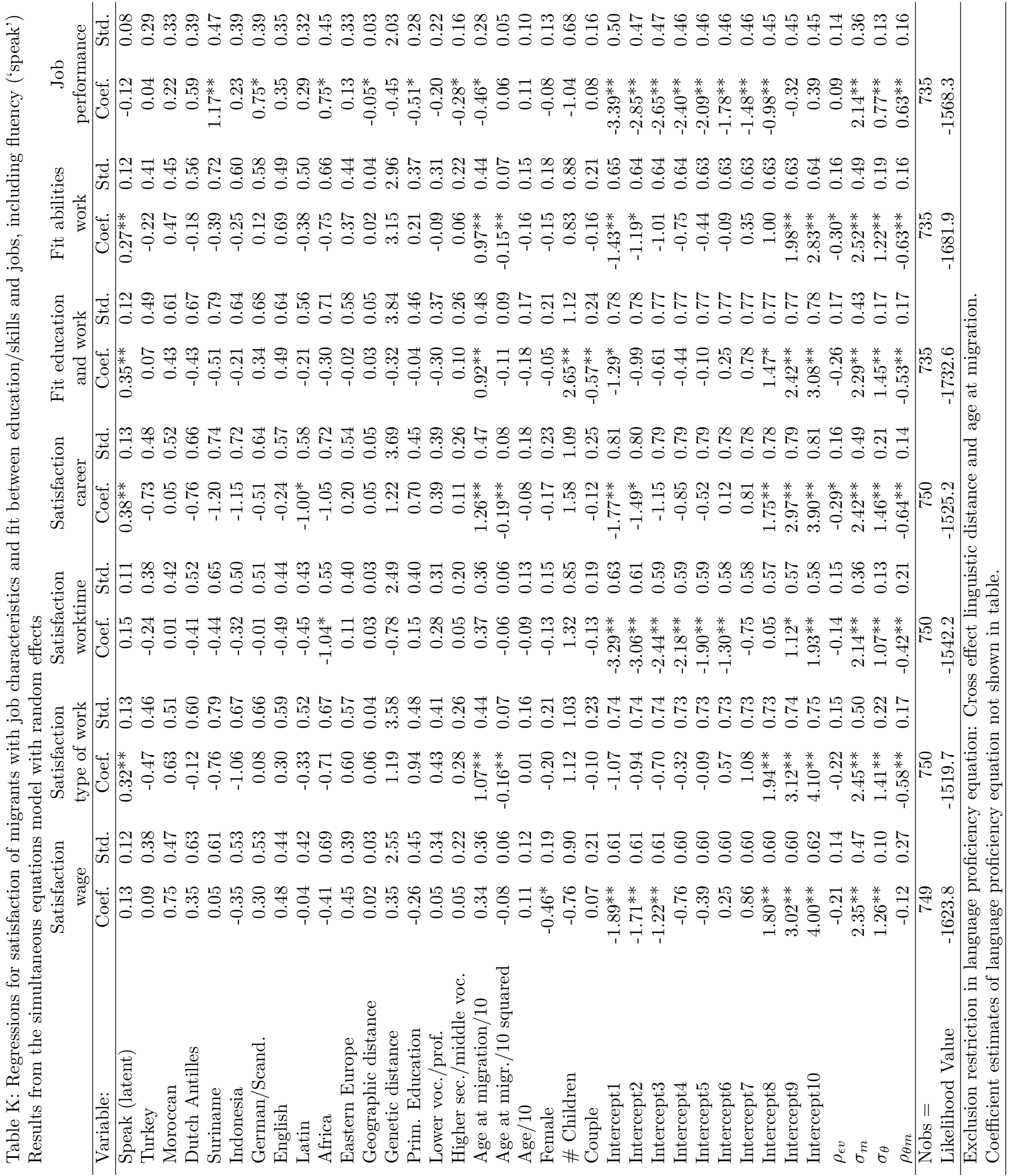




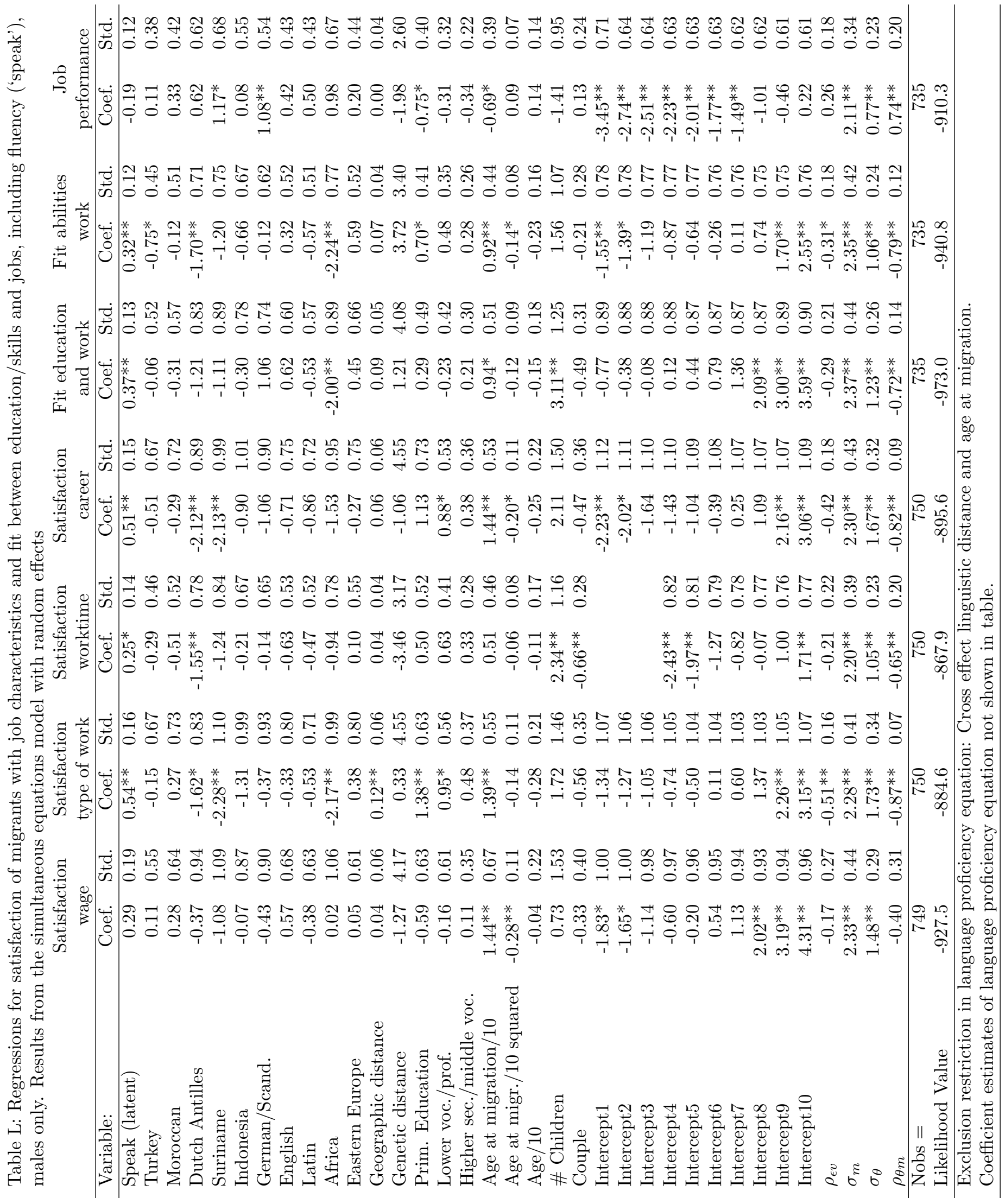




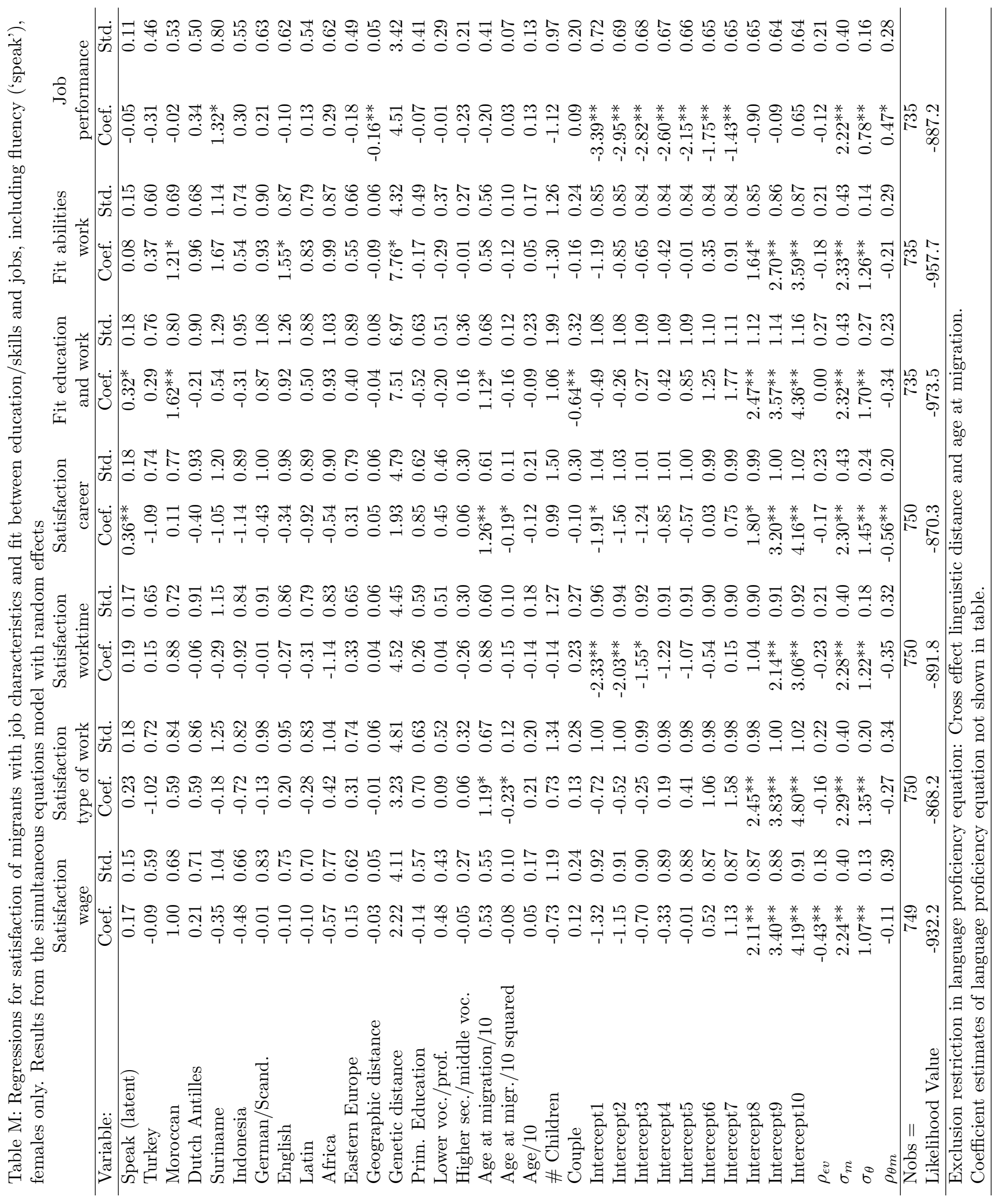


Table O: Sample statistics professional level

\begin{tabular}{|c|c|c|c|c|c|c|}
\hline & \multicolumn{2}{|c|}{ Both genders } & \multicolumn{2}{|c|}{ Male } & \multicolumn{2}{|c|}{ Female } \\
\hline & Native & Migrant & Native & Migrant & Native & Migrant \\
\hline Number of observations (NT): & 13,538 & 920 & 6,383 & 418 & 7,155 & 502 \\
\hline \multicolumn{7}{|l|}{ Professional level: } \\
\hline Higher academic or independent profession & 6.8 & 8.0 & 9.4 & 9.3 & 4.5 & 7.0 \\
\hline Higher supervisory profession & 8.3 & 5.8 & 12.8 & 9.1 & 4.2 & 3.0 \\
\hline Intermediate academic or independent profession & 25.4 & 21.4 & 17.0 & 14.4 & 32.9 & 27.3 \\
\hline Intermediate supervisory or commercial profession & 14.0 & 8.8 & 18.4 & 9.8 & 10.1 & 8.0 \\
\hline Other mental work & 24.9 & 24.4 & 15.1 & 15.6 & 33.7 & 31.7 \\
\hline skilled and supervisory manual work & 7.0 & 6.5 & 13.1 & 13.4 & 1.6 & 0.8 \\
\hline Semi-skilled manual work & 6.8 & 9.8 & 9.8 & 17.0 & 4.1 & 3.8 \\
\hline Unskilled and trained manual work & 5.2 & 12.8 & 2.2 & 7.7 & 7.8 & 17.1 \\
\hline Agrarian profession & 1.7 & 2.5 & 2.3 & 3.8 & 1.2 & 1.4 \\
\hline Total bottom 3 categories: & 13.7 & 25.1 & 14.3 & 28.5 & 13.1 & 22.3 \\
\hline \multicolumn{7}{|l|}{ Further explanation levels: } \\
\hline Professional level & \multicolumn{6}{|l|}{ e.g. } \\
\hline Higher academic or independent profession & \multicolumn{6}{|c|}{ architect, physician, scholar, academic instructor, engineer } \\
\hline Higher supervisory profession & \multirow{2}{*}{\multicolumn{6}{|c|}{$\begin{array}{l}\text { manager, director, owner of large company, supervisory civil servant } \\
\text { teacher, artist, nurse, social worker, policy assistant }\end{array}$}} \\
\hline Intermediate academic or independent profession & & & & & & \\
\hline Intermediate supervisory or commercial profession & \multicolumn{6}{|c|}{ head representative, department manager, shopkeeper } \\
\hline Other mental work & \multirow{2}{*}{\multicolumn{6}{|c|}{$\begin{array}{l}\text { administrative assistant, accountant, sales assistant, family carer } \\
\text { car mechanic, foreman, electrician }\end{array}$}} \\
\hline skilled and supervisory manual work & & & & & & \\
\hline Semi-skilled manual work & \multicolumn{6}{|c|}{ driver, factory worker } \\
\hline Unskilled and trained manual work & \multicolumn{6}{|l|}{ cleaner, packer } \\
\hline Agrarian profession & \multicolumn{6}{|c|}{ farm worker, independent agriculturalist } \\
\hline
\end{tabular}




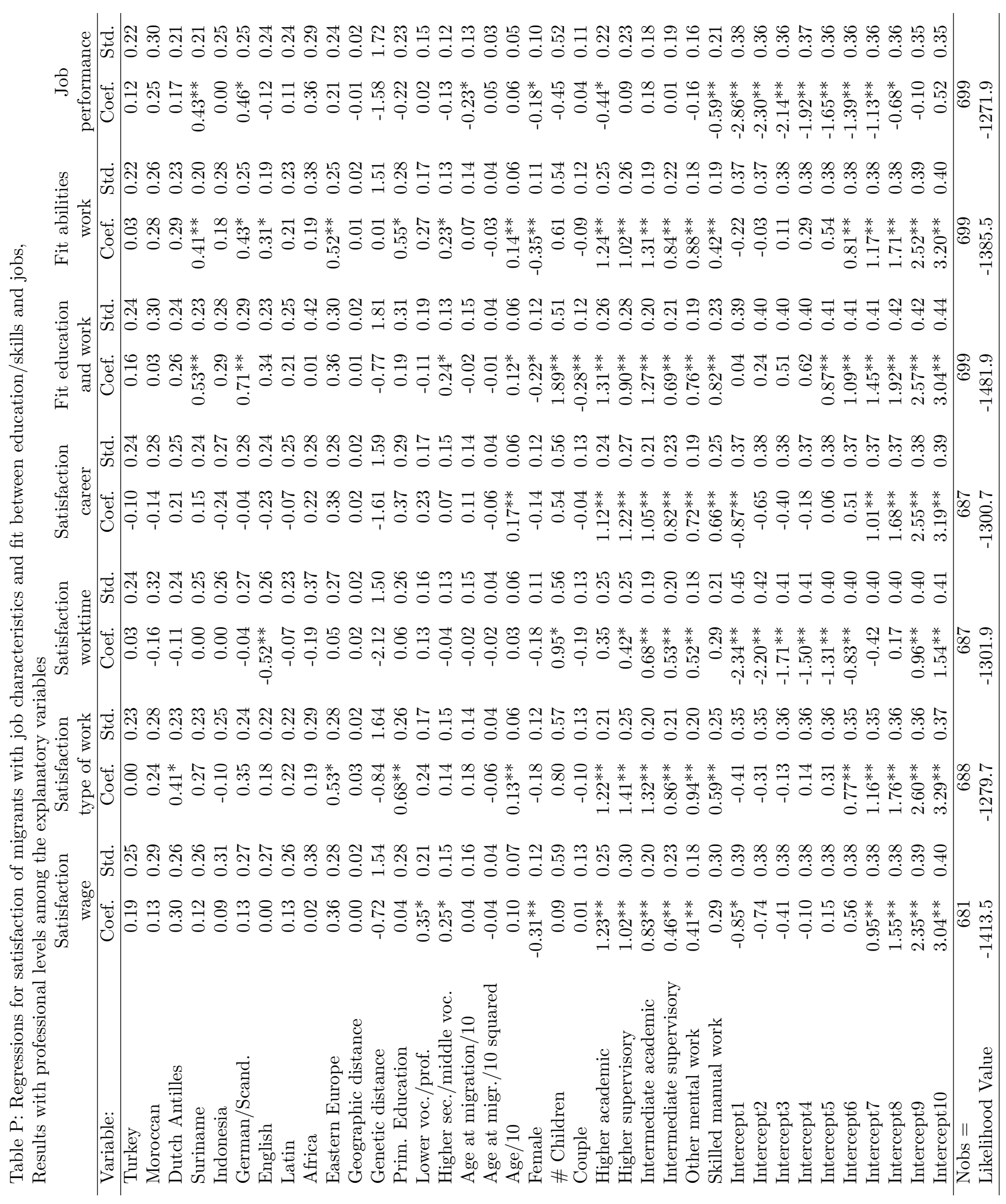




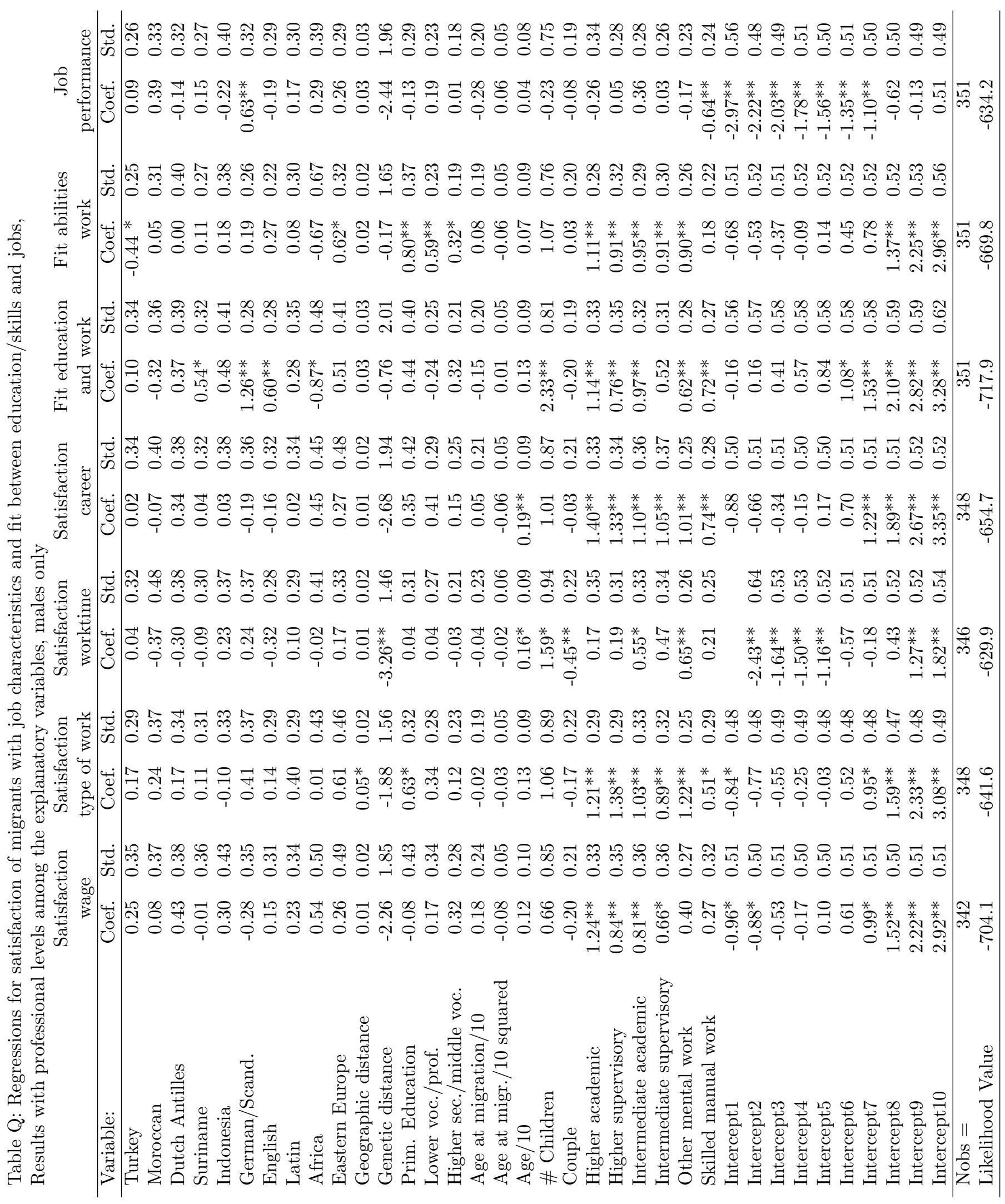




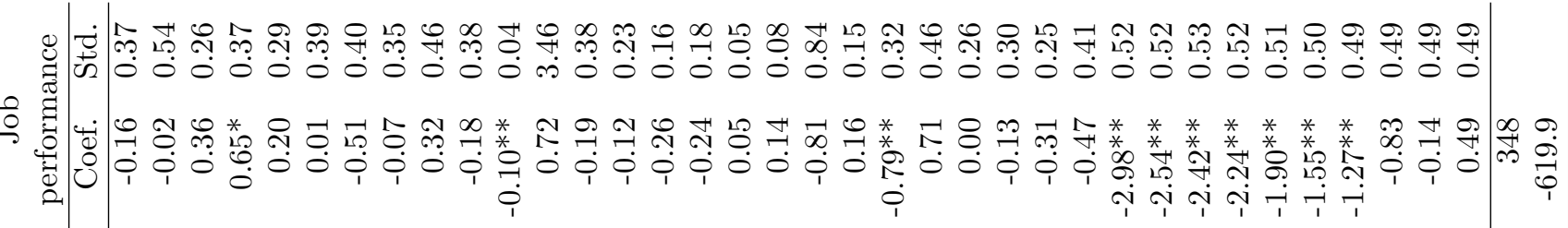

凹

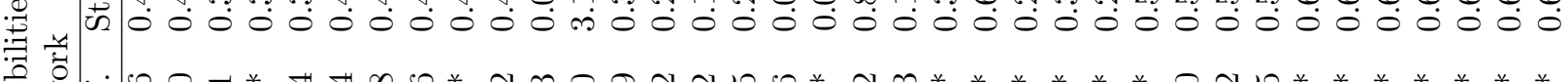

تृี

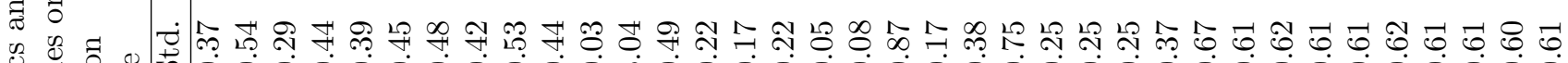

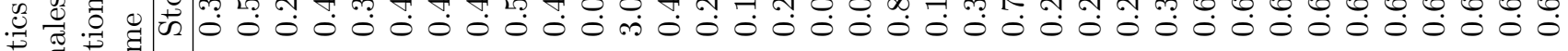

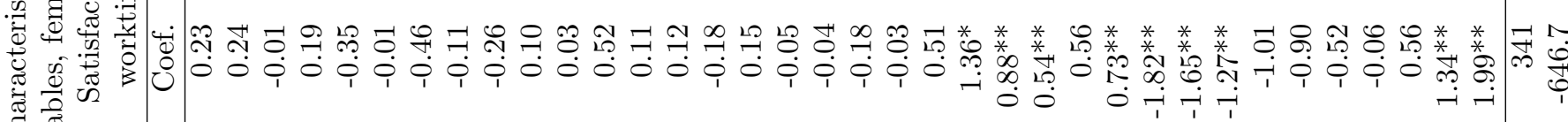
.

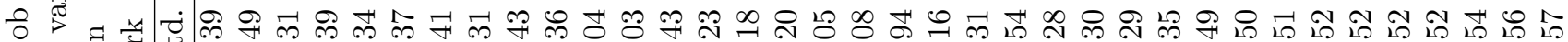

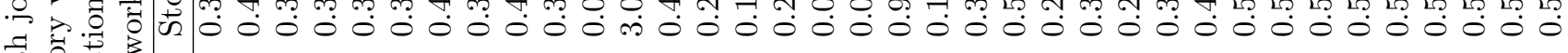
要

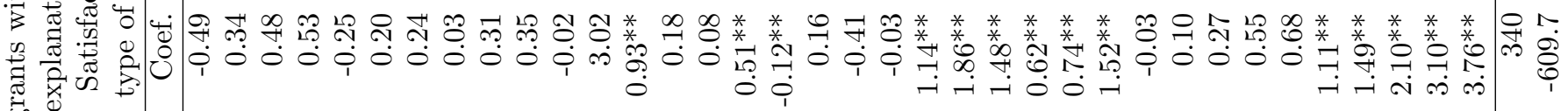
.

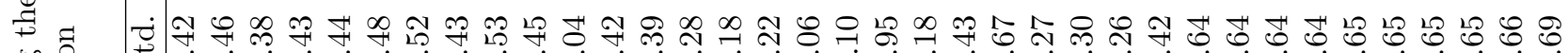
प

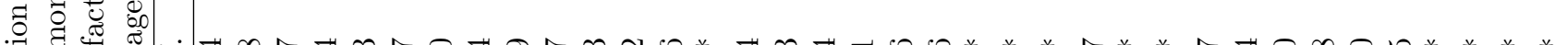

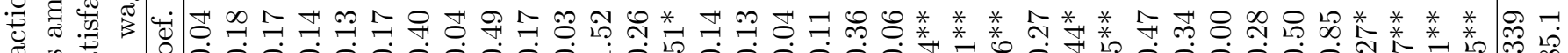

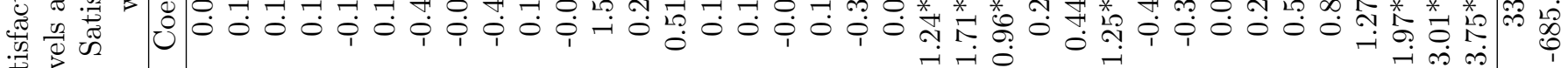
焉

$\dot{0} \overline{0}$

?.

.

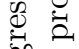

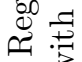

$\ddot{3}$

吾

ज्ञ

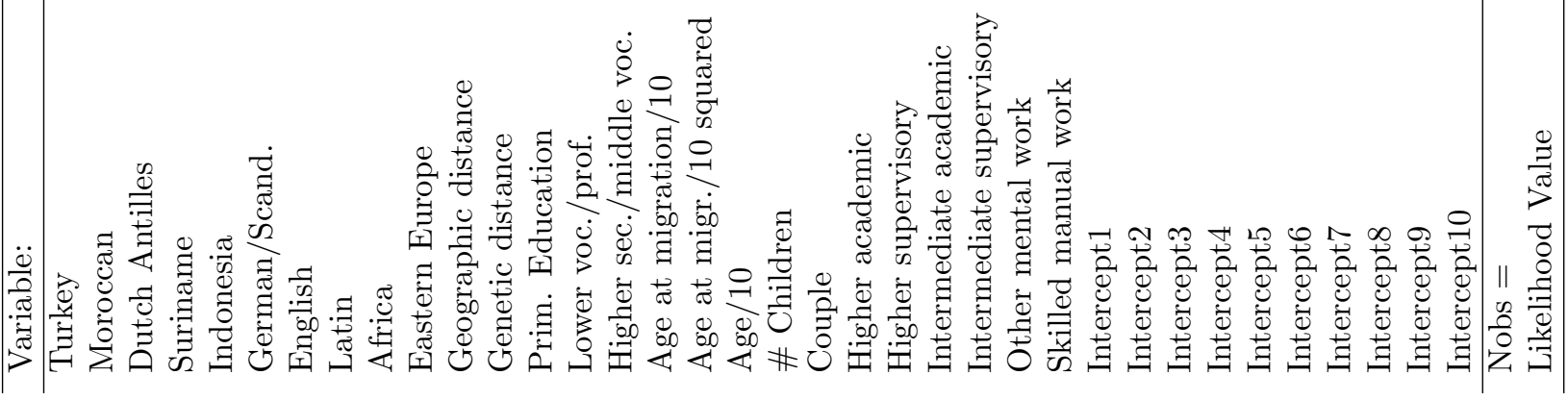

